\title{
A Three Decades of Marvellous Significant Review of Power Quality Events Regarding Detection \& Classification
}

\author{
Mian Khuram Ahsan, Tianhong Pan*, Zhengming Li \\ School of Electrical Information \& Engineering, Jiangsu University, Zhenjiang, China \\ Email: *myblackeyes4u@qq.com
}

How to cite this paper: Ahsan, M.K., Pan, T.H. and Li, Z.M. (2018) A Three Decades of Marvellous Significant Review of Power Quality Events Regarding Detection \& Classification. Journal of Power and Energy Engineering, 6, 1-37.

https://doi.org/10.4236/jpee.2018.68001

Received: June 17, 2018

Accepted: July 29, 2018

Published: August 1, 2018

Copyright ( 92018 by authors and Scientific Research Publishing Inc. This work is licensed under the Creative Commons Attribution International License (CC BY 4.0).

http://creativecommons.org/licenses/by/4.0/

\begin{abstract}
Around the globe, the necessity of green supply with a dedicated standard quality thrust of consumers is increasing day by day. The advancement in technology urges the electrical power system to deliver a high-quality rated undistorted sinusoidal current, the voltage at a constant desired standard frequency to its consumers. The present paper reveals a complete and inclusive study of power quality events, such as automatic classification and signal processing via creative techniques and the noises effect on the detection and classification of power quality disturbances. It's planned to make a possible list for quick reference to obtain an extensive variety on the condition \& status of available research for detection and classification for young engineers, designers and researchers who enter in the power quality field. The current extensive study is supported by a critical review of more than 200 publications on detection and classification techniques of power quality disturbances.
\end{abstract}

\section{Keywords}

Power Quality, Feature Extraction, Power Quality Disturbances, Power Quality Events Classifier

\section{Introduction}

The economy of any stable country is mainly dependent on the power generation and its demand and supply. It greatly suffers from massive losses when in the power delivery there are some abnormalities such as disturbance/deviation in the frequency, current, voltage from the official rating. These power qualities result in malfunctioning failure of electronic and electrical equipment. The sizes and smartness in the business environments required more sensitive compo- 
nents such as computers, protection relay equipment and PLCs which are the biggest sources of power consumption [1]. Power quality is discussed in researchers/scientist on a daily basis worldwide since 1970 and it's one of the hot topic in all decades due to upcoming new trends and technologies [2] [3]. Consumers are expecting un-interrupted and high-quality power for their household and business equipment. The integration of resources of renewable energy in distribution grids according to user's expectation is the central focusing area of smart grid and a great challenge for all engineers \& scientists [4]. Sometimes huge and small blackouts happen due to the interdependencies of associated dynamical propagation and its sub-networks because of different power quality disturbances [5]. To prevent such issues consumers are investing huge investment in personal, uninterrupted power supplies though they are very costly; it shows the importance of commercial energy distribution regarding power quality [6]. Problems such as swell/sag, harmonics, flickers, voltage regulation, deviation in phase, unbalancing loads and frequency errors are exaggerated in the distribution system due to the increase of electronically switched and nonlinear devices which well equipped the smart transmission systems and renewable energy integration. In the last two decades, the international scientific community studied, proposed and developed several solid-state power electronic devices to improve power quality [7] [8]. The induction of these devices in the system attracts the attention of engineers towards the complexity of networks for planning and operation of electrical supply with the quality of power [9]. In electrical systems during the operating conditions such as network contingencies, load disturbances, renewable energy resources which output the power sinusoids and harmonics are observed at low-frequency signals while across the bus/node when electronically controlled capacitors are switch, and the transient oscillation is glimpsed in power network [10] [11] [12] [13] [14]. The consumer's bears ancillary services costs due to these unwanted events such as load curtailment loss, reactive power cost, disturbance removing cost and re-dispatch cost. Therefore PQ events need to maintain standards of the power supply and to be monitored and mitigated in operating conditions. The Large power system is complex during operations for monitoring and analysis to measure all PQ events. Therefore under sudden changes of operating conditions an elegant tactics \& tools are requisite for detection and its classification also to understand smartly the utilities, regulators, and consumers operating requirements [15]. Power quality issues can be created from any reason that can be minor to major but in all cases it affects the system with prodigious losses. In the next generation of power grid networks the premier task is to localize the proximity of problem regardless of its nature, secondly how to respond reliably and securely to the detected regions which has been impacted by faults. Power quality becomes more challenging and complex in the presence of dual and multi disturbances. There are many challenges to focus specially to achieve integration of multi-platforms, diagnostic modular designs to achieve flexibility, precision, fast $\&$ accurate results with reliability. It is 
important to note that due to the introduction of nanotechnology the systems are getting more and more complex which needs a system which can automatically detect, classify and reserve power quality. In this aspect maybe in future the Multi agent system can take a leading role to achieve the accuracy and computational time on the basis of Control \& Decision integration with support of Power Quality Decision Data Bank (PQDDB). The PQDDB is a new term introduced here on the basis of Power quality verities which are introduces every day via numerous researchers. These verities can be combined in the form of Power quality directory with decision and to feed to data bank of system as ready reference. This single platform will directly impact the approach, computational time and the accuracy. However, to make analysis more efficient requires reason of event occurrence and foremost from these disturbances feature extractions are requisite for precise and accurate detection [7]. After that these extracted features can be used for classification process in a sophisticated way.

\section{The Realization of Power Quality Events}

\subsection{Power Quality}

In Power network system the term "Power Quality" is used for the occurrence of electromagnetic Phenomena as wide variety [5]. Quality of Power supply is term as the ability of the system to deliver a signal containing undistorted current, voltage, and frequency [16]. The power quality sensitivity is classified in a highly evolved electrical system in three categories: 1) digital economy; 2) continuous processing economy; 3) essential services economy. The loads vary from 03-120 KVA per event, and there is a liability cost incurred on all above categories to operate. The variation in characteristic of current and voltage can shutdown or damage the electrical equipment which is critically design for specific tasks. Such continuous changes in the power supply with such frequency can despise the image in a competitive environment [16]. To PQ issues significantly affects Energy industries and their economic operations. To mitigate these problems the consumers apart from grid supply are equipped with backup instruments [17]. IEEE standard 1159-1995 [18] includes a broad variety of power quality disturbances such as Impulsive transients, oscillatory transients, sag, swell, interruption (with short duration variations) flickers, notch, harmonics (steady state variations) large period variation, frequency variation. In [19] the disturbances of power quality are defined in standards of UNE which is given in Table 1. Power quantities under balance \& unbalance conditions sinusoidal \& nonsinusoidal measurement definitions are include in IEEE Std. 1459-2010 [20]. As a part of a power quality Improvement structure, the power magnitude measurement system was presented in IEEE Std. 1459 [21] [22], while in [23] for the electrical power quantities measurements standard definitions under sinusoidal, balanced and non-sinusoidal, unbalanced conditions given as per revision IEEE Std. 1459-2010; March 2010 by the Author. In [24] the author presented a real power quality measurement via an adaptive algorithm subject to IEEE std.1459-2000. 
Table 1. Classification of PQ disturbances [19].



\subsection{Classifier's Based on Automatic Power Quality Events}

Before 1990's due to the unavailability of advanced techniques such as signal processing few physical pattern systems were brought into play for managing \& monitoring of power supply qualities. With the passage of time, the technology evolved as smart technologies and was adopted with time to time such as artificial intelligence Internet-networking, pattern-recognition, data mining as a smart signal processing techniques. The smart gadgets, such as digital signal processors in computers, information \& communications buffers, mass storage, etc. Segmentation and feature extraction are the two function blocks of an automatic PQ event classifier as shown in Figure 1 [25] the signal is pass through the pre-processing unit for classification, and the post-processing gives the decision about types of disturbance.

\subsection{The Segmentation}

Segmentation is a process which breaks up the information succession into stationary as well as non-stationary parts [26]. In between transition-segment events and the segments is to distinguish between the disturbances into different types the information of feature extraction from the event part is important because the information is unique during signal is stationary. To get the episode of 


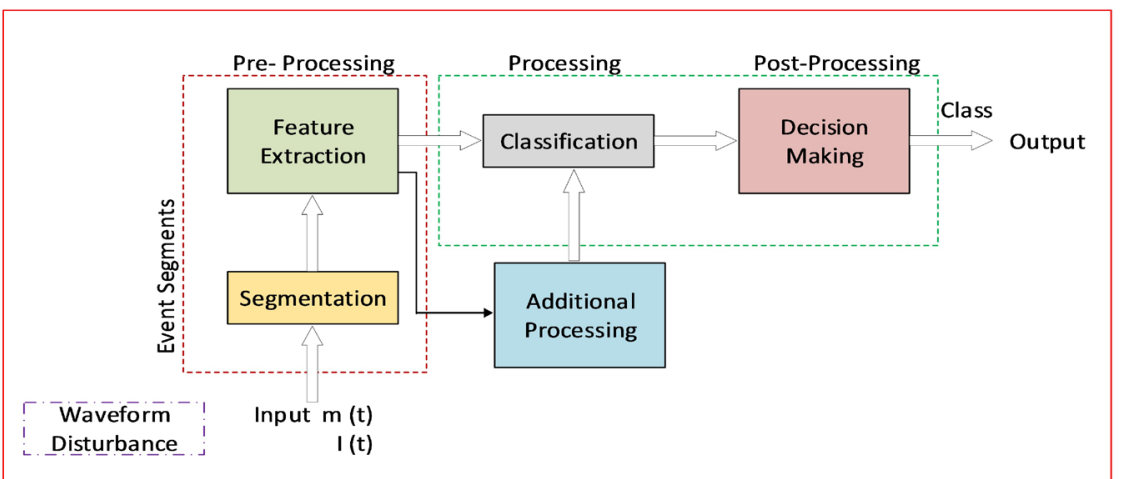

Figure 1. Block diagram of automatic power quality event classifier.

disturbance waveform a technique of triggering need compulsory to acquire the start and end spots of the power quality events [27] [28]. The method in current scenario utilized for identifying Power classes is supported on next cycle point to point comparison or RMS values spot to spot assessment to the distorted signal with its transformed frequency domain data or pure signal. The recently proposed methods are classified as model-based (Parametric) or transform supported as (nonparametric). The Auto-regressive (AR) and Kalman filter (KF) are parametric methods while Wavelet transform (WT) and Short-term Fourier transform (STFT) is nonparametric methods [29].

\section{The Feature Extraction}

Detection of disturbance is also known as the extraction of features from power quality disturbances. The human brain is liable source of the interface which extracts the electrical features from Electroencephalogram signals [30]. In the same way, these extracted features are use in the classification of Power quality events. A post-processing unit is use for making a final judgment via the information of the classifier's [25]. In classification the selection of suitable extracted features play a major role, it may be derived from the parameter of signal model or the original dimension or to get it from some malformed sphere [31]. In subsection, the current progress concerning the feature extractions practices is present in detailed.

\subsection{Methods Based on Hilbert Huang Transform}

In 1998 Dr. Huang proposed a novel signal processing algorithm known as Hilbert Huang transform (HHT) which includes two processes [32]. The empirical mode decomposition (EMD) and Hilbert transform works in a combination that empirical mode decomposition process into IMF (intrinsic mode function) which has significant instantaneous amplitude and frequency [33]. The empirical mode decomposition disbands the signals into different intrinsic mode roles in an approach that these frequencies were arranged from higher to lower. To achieve instantaneous frequency and amplitude versus time curve the Hilbert transform is applied once the signal is dissolve into different IMF's [34] [35]. In 
the development of different circumstance of PQ detection and classification numerous HHT variants are establish, even for the assessment of power events the EMD and Hilbert transform combination based method is developed in [36]. Furthermore an approach of using Relevance Vector machine along with HHT is presented in [37] for power quality disturbances classification. The HHT algorithm is utilize for the sophisticated power quality through multi-disturbances signal HHT detection method in [38]. In the scrutiny of non-stationary and nonlinear signals the HHT cannot be used, so to analyze a voltage flicker the Orthogonal Hilbert Huang transform (OHHT) was use in [39]. By HHT and Mathematical morphology, the author presented a novel method for power quality disturbances detection and analysis' in [40], while the author introduced the time-frequency analyses with the support of Hilber-Haung modified method for distorted power signals [41]. An improved methodology in radial basis function (RBF) neural network is used to classify while to extract proficient features of the power quality via Hilbert Transform is presented in [42].

\subsection{Methods Based on S-Transform}

The S-transform was created through the blend of STFT and WT which is a time-frequency tool [43]. The Gaussian modulated co-sinusoids is the primary function of S-transform, it creates a time-frequency representation of a time series. In this frequency-dependent resolution combines exclusively that simultaneously localizes imaginary and the real spectra [44]. While in [45] this method features are extracted through S-transformation of the voltage signal which uses fewer features and little memory. The S-transform provides a pattern in case of non-stationary disturbance with boisterous information (noisy data) that resemble closely to the distress type which may necessitate an uncomplicated classification course of action [46]. In [47] a particular feature with a favorable value is determined for the width factor by estimating the classification accuracy. The Author presented in [48] an efficient and straightforward method for power quality disturbances while using S-transform for quantification and classification into ten typical kinds. While in [49] the author used the dynamics to reduce the run time by introducing the amalgam techniques on S-transform \& dynamics for real-time classification of power quality disturbances. The automatic classification of power quality disturbance is presented in [50] via S-transform supported neural networks configuration; it integrates neural networks and S-transform techniques to construct a classifier for multiple level observation. Discrete orthogonal S-transform is use for power quality analysis in [51]. In [52] for power quality events the multi-resolution S-transform is propose which is supported by the fuzzy recognition system, which changes the variable width of widow analysis concerning frequency subject to a user-defined function. In [53] to extract accurately the localized time of spectral characteristics for non-stationary signals the discrete S-transform (FDST) algorithm is proposed. In this paper [54] for detection and classification of PQ two clustering decision trees methods has 
been compared which are S-transform \& fuzzy C-means while other is S transform with rule-based in line with Std IEEE 1159 using software of Matlab. While in [55] the author presented a rule-based tree with the help of ANN and S-transform which further improved in [56] to rule based tree with the only S-transform.

\subsection{Methods Based on Wavelet Transform}

The Wavelet transform (WT) relies on a group theory and a square-integral representation, in other words, it's a mathematical instrument, in similar to FT, which expand a signal prototype function by decomposition of a signal into multiple levels of resolution. It provides frequency and time local representation of a given signal. In disturbances of power quality such as transition where time-frequency analysis are required it's more beneficial [57] [58]. The Wavelet transform is classified into continuous wavelet transforms (CWT) and discrete wavelet transform (DWT) [59]. In this [60] paper DWT based techniques for operational events of power system detection along with all associated disturbances is presented. The signals decompositions of multi-resolution are introduced as prevailing investigation apparatus for Power quality event in [61]. In [62], a wavelet-based method is used for detection, classification and quantifying along with localizing is presented. A compression method for power quality disturbances data is introduced via wavelet packet transform (WPT) and DWT in [63]. The architectural model which is a two-layer probabilistic wavelet network is proposed in [64] which includes the probabilistic network and a wavelet layer for disturbance detection of voltage harmonics. Consequently, in [65], self-organizing learning array system with Wavelet transform novel approach is used for the power quality disturbance classification. A unique viewpoint for the IEEE standards 1459-2000 definitions is brought in by the author in [66] by using the SWT for defining pollution factor, power factors and control components. The time-frequency domains are redefined while using WPT in [67] which PQ was recommended in [68] [69]. In [70] wavelet norm entropy for power disturbance classification is presented based on effective feature extraction method. WT and S-transform based method is proposed by the author in [71] which detect the interference in distributed generation hybrid system due to load rejection in islanding. The author presented a method by using complex wavelet coefficients to the un-decimated wavelet transform to compute Power qualities in [72], to use wavelet method is a critical issue because the selection of suitable wavelet is an important task because with the increase in filter length the computational cost increases. In this paper [73] the features are extracted by discrete wavelet transform with (MRA) multiresolution Analysis through an optimal feature selection of Power quality disturbances through (PNN-ABC) probabilistic neural network supported by artificial bee colony. In the system due to the severity of the faults many long and short duration events are caused by the power quality [74]. To accurately extract the component of fundamental 
frequency from the distorted input signal the filter design and its Q-factor and redundancy are more important [75]. These machines sometimes contradict with actual system conditions [76]. In [77] a classifier of power quality is proposed which is supported by WT and SVM to analyze complex events via a combination of binary classifiers which contains real signals magnitude comprising of events within the analyzed temporal window. In [78] mapping power quality events which are momentary variation regarding disturbances are crucial aspect while in [79] power quality events which are non-stationary are analyzed via MRA and Discrete wavelet transform. In this paper [80] for the wavelet-based feature extraction techniques is used via these three methods which are SVM (support vector machine), DT (decision tree), and RF (random forest). The primary challenges are concerning the researchers are due to the changing regulation, because the distribution market is liberalize with the increase of equipment based on power electronics. The issue of the day is to extract features from the limited measurements [81]. While in [82] the Author presented for detection and localization MODWT technique which is time-series based maximal overlap. The author proposed in [83] an integrated rule base approach of DWT and FFT for the detection of power quality. To achieve the detail coefficient features the discrete wavelet coefficients are utilized to get the average energy entropy of squared. Table 2 provides the characteristics of commonly use wavelets.

\subsection{Methods Based on Fourier Transform}

Fourier transform (FT), is the frequency domain analysis technique where the signal has represented a combination of multiple frequencies of different terms of sinusoidal [84]. Fourier transform is use in extracting spectrums for stationary signals at specific frequencies; however with fluctuation some temporary information is associated which is yet unable to resolve [84]. The short time Fourier transform (STFT) is one of the FT variants which divides the signal into small segments and considers that it is in stationary [85]. As for the signal changes over time, the STFT determines the Phase contents and the sinusoidal frequency of local sections. It also analyzes several frames of an extracted signal a window which moves with time. The time and variance of frequency relation can be determined through a moving window [86] [87]. It is complicated for STFT to scrutinize non-stationary signals [88]; however, it has been applied in a fixed window size to non-stationary signals while operating [89]. Non-stationary signals are analyze via time-frequency analysis through Discrete STFT. The Discrete STFT putrefies the signals of varying Time in components of time-frequency domain [90]. The discrete signals which were symbolized by DFT (Discrete Fourier transform) go over themselves from positive to negative infinity in a periodic fashion while the same results exhibit by fast Fourier transform (FFT) in less time than DFT [91]. The author is using Wavelet Transforms (WT) \& Fourier methodologies in [92] to extract recorded current and voltage waveform. 
Table 2. Wavelet characteristics.

\begin{tabular}{|c|c|c|c|c|c|c|}
\hline Sr. No & $\begin{array}{l}\text { Wavelet } \\
\text { Name }\end{array}$ & $\begin{array}{l}\text { Filters } \\
\text { Length }\end{array}$ & $\begin{array}{l}\text { Compact } \\
\text { Support }\end{array}$ & $\begin{array}{l}\text { Width } \\
\text { Support }\end{array}$ & $\begin{array}{l}\text { Orthogonal } \\
\text { Properties }\end{array}$ & Symmetry \\
\hline 1 & Coiflets & $6 \mathrm{~N}$ & YES & $6 \mathrm{~N}-1$ & YES & $\mathrm{NO}$ \\
\hline 2 & Daubechies & $2 \mathrm{~N}$ & YES & $2 \mathrm{~N}-1$ & YES & $\begin{array}{l}\text { Near to } \\
\text { Symmetry }\end{array}$ \\
\hline 3 & Symlets & $2 \mathrm{~N}$ & YES & $2 \mathrm{~N}-2$ & YES & $\begin{array}{l}\text { Near to } \\
\text { Symmetry }\end{array}$ \\
\hline 4 & Haar & 2 & YES & 1 & YES & YES \\
\hline
\end{tabular}

In [93] the author for the judgment of power quality used "Windowed FFT" which is the time version of discrete time Fourier transform [94]. In this paper [95] the author presented a method which analyzes the disturbances of power quality via FFT which suffer spectral leakage phenomenon which results in invalid assessment in the existence of power quality which is non-stationary, while this paper calculates and analyzes synthetic signals while offline [96]. In this article, a modified FNN (Fourier neural networks) and HST (hyperbolic S-transform) are presented better time-frequency resolution [97]. In this article [98] the FRFT (Fractional Fourier transform) which is a new technique, offers multi-domain feature extractions. It is verified through different research that WT is healthier than STFT. Many schemes have been developed to detect power quality based on STFT, Kalman filter, and S-transform.

\subsection{Miscellaneous Feature Extraction Techniques}

The methods mentioned in section A-D apart from that there are some other methods for detection and classification which also played a unique function in the improvement of power quality. In [99] for monitoring of power quality, an author demonstrated de-noising method supported by change point impends regarding wavelet base power quality. In [100] the author presented feature extraction of power quality disturbances by parallel computing for time-frequency. In [101] frequency shifting decomposition with Hybrid wavelet and HT for Power quality analysis is presented. Many other techniques such as short-time correlation transform [102]. Curve fitting [103], linear combiners [104], Adeline [105], digital filters [106], parametric spectral estimation method [107], Gabor-Wigner transform (GT) [108], TT Transform [46], Fuzzy-ARTMAP-wavelet network [109], Kalman filter [110] [111], extended Kalman filtering [112], DWT Transform and wavelet network [113], Hybrid soft computing technique [114], higher order statistics and case-based reasoning [115]. In [116] the advantage of deep learning is utilized on image file classification, the image files are of three-phase power quality events data, while in [117] a staked autoencoder is used as a deep learning framework for the classification of power quality distribution. In [118] the proposed method decouples the signal of the power system into independent 
components and then classifies power quality disturbances by specialized classifiers. The anomalies in power quality time series are presented in this paper [119]. This article is based on MMG (multi-resolution morphology gradients) [120], but its process uses half the MMG strategy. In [121] paper k-mean optimization algorithm is presented which classify PMU (Phasor measurement units) into different power quality classes. In [122] the author tried to use different models to get results with the help of Multi agent system the results are shown in Figure 2 and Figure 3. These authors have co-operated a vital role in recent years to improve event detection and classification of Power quality.

\subsection{Detection Techniques Comparative Study of Power Quality Event's}

In Table 3 all the main detection techniques of power qualities computational efficiency is presented to detect Power quality, while in Table 4 the analysis of all the main methods of power quality comparison is presented. By the publication [32]-[121], critical review comparative study of detection techniques of power quality events is carried out.
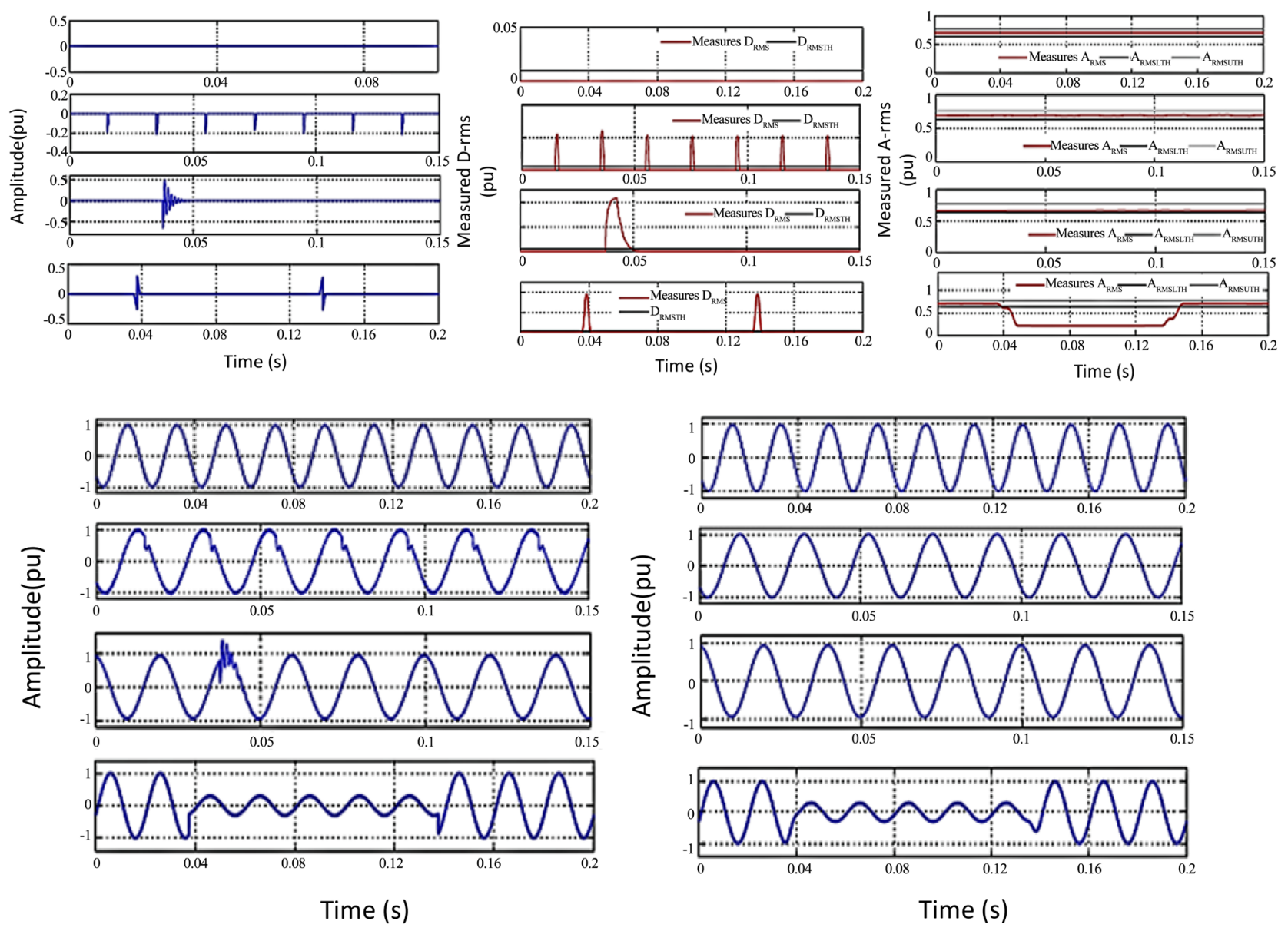

Figure 2. Fundamental, normal, oscillatory transients, voltage sag, and notch sag. Signals with extracted feature along with signal feature measured rms envelope, with extracted approximation and approximation signal measured rms envelope. 
Promenten

I:" thaman

ladena

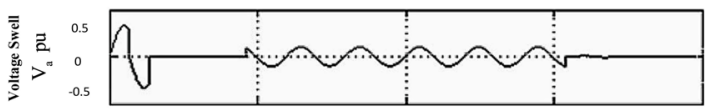

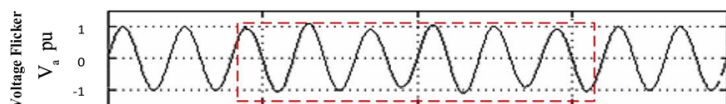



: $:$ : ena



MNANANA



1:NuNNor

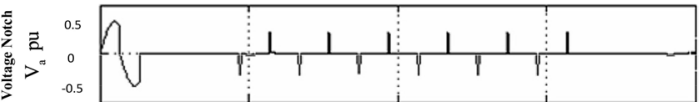

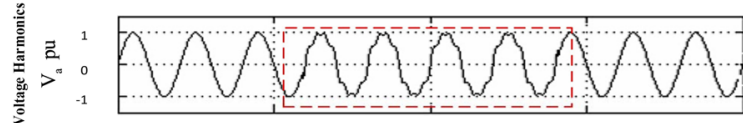

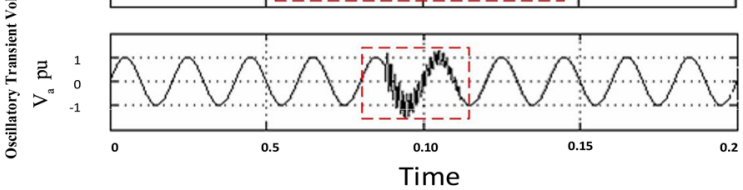

(a)



(b)



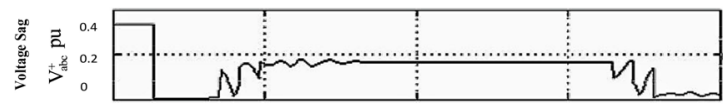

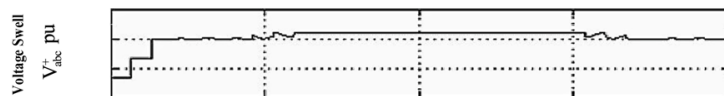




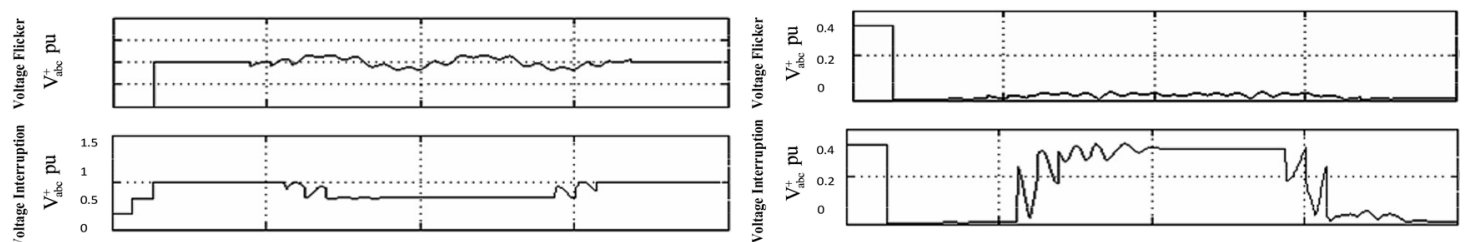

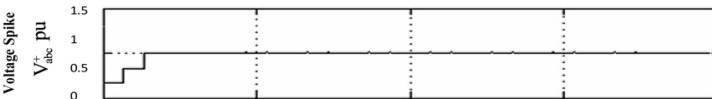

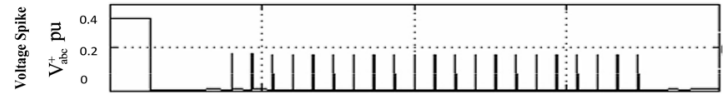



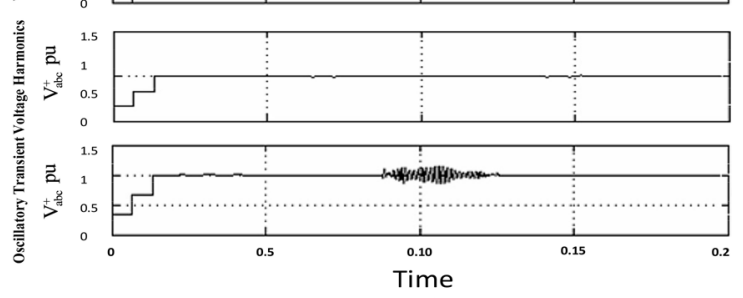

(C)

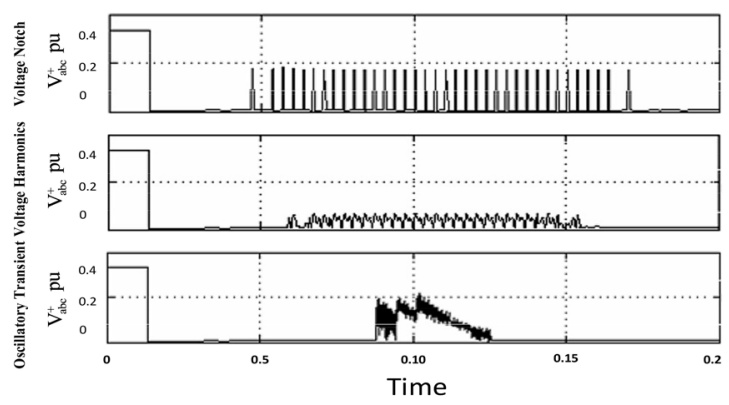

(d)

Figure 3. (a) Different power quality disturbances; (b) Phase disturbances; (c) Positive instantaneous peak contour; (d) Negative instantaneous peak contour. 
Table 3. Power quality techniques computational efficiency.

\begin{tabular}{cccccc}
\hline \multirow{2}{*}{ SR-No. } & $\begin{array}{c}\text { Power Quality } \\
\text { Disturbance }\end{array}$ & \multicolumn{4}{c}{ Power Quality Detection Techniques Efficiency in Percentage } \\
\cline { 3 - 6 } & $\begin{array}{c}\text { Discrete Wavelet } \\
\text { Transform [36] }\end{array}$ & $\begin{array}{c}\text { Fast Fourier } \\
\text { Transform [36] }\end{array}$ & $\begin{array}{c}\text { S-Transform } \\
{[113]}\end{array}$ & $\begin{array}{c}\text { Hilbert Haung } \\
\text { Transform [218] }\end{array}$ \\
\hline 1 & Flicker & 98.67 & 89 & 100 & 100 \\
2 & Notch & 97.33 & - & 83 & 100 \\
3 & Sag & 98.67 & 95 & 100 & 100 \\
4 & Swell & 99.33 & 98 & 100 & 100 \\
5 & Transient & 98.67 & 100 & 100 & 98 \\
6 & Harmonics & 99.33 & 100 & 100 & 95 \\
7 & Spike & - & - & 77 & 95 \\
8 & Sag + Harmonics & 98.18 & - & 100 & 98 \\
9 & Swell + Harmonics & 98.18 & - & 100 & 89 \\
10 & Sag + Transients & 98.36 & - & - & - \\
11 & Swell + Transients & 98.18 & - & - & - \\
\hline
\end{tabular}

Table 4. Power quality primary methods comparison analysis.

\begin{tabular}{|c|c|c|c|}
\hline \multirow{2}{*}{\multicolumn{2}{|c|}{$\begin{array}{l}\text { Power Quality } \\
\text { Sr. No Analysis } \\
\text { Techniques }\end{array}$}} & \multirow{2}{*}{ Advantages } & \multirow[b]{2}{*}{ Disadvantages } \\
\hline & & & \\
\hline 1 & $\begin{array}{l}\text { Short Time } \\
\text { Fourier } \\
\text { Transform }\end{array}$ & $\begin{array}{l}\text { It's simple in implementation; it is } \\
\text { used in stationary signals successfully } \\
\text { whose properties do not change in } \\
\text { time. }\end{array}$ & $\begin{array}{l}\text { It has a fixed window width } \\
\text { limitation which does not follow } \\
\text { signals dynamics appropriately } \\
\text { therefore it's not suitable for non } \\
\text { stationary signals. }\end{array}$ \\
\hline 2 & $\begin{array}{l}\text { Hilbert Huang } \\
\text { Transform }\end{array}$ & $\begin{array}{l}\text { Phase and instantaneous amplitude } \\
\text { can be simply assessed due it } \\
\text { generation of quadrature signals. It's } \\
\text { very useful in distorted waveforms to } \\
\text { extraction of features. }\end{array}$ & $\begin{array}{l}\text { It used to works only in narrow band } \\
\text { conditions which is very limited. }\end{array}$ \\
\hline 3 & S-Transform & $\begin{array}{l}\text { It's very flexible it can easily } \\
\text { convertible in } 2-\mathrm{D} \text { frequency } \\
\text { translation domain from time } \\
\text { domain and even to Fourier } \\
\text { frequency domain. }\end{array}$ & $\begin{array}{l}\text { The reliance of frequency window } \\
\text { width on central frequency generates } \\
\text { inaccurate measurements of } \\
\text { harmonics. It also does not gratify } \\
\text { real-time necessities subject to block } \\
\text { processing manner. }\end{array}$ \\
\hline 4 & $\begin{array}{l}\text { Wavelet } \\
\text { Transform }\end{array}$ & $\begin{array}{l}\text { It is suitable in an excellent } \\
\text { time-frequency resolution it also } \\
\text { provides in time as well as frequency } \\
\text { the local representation. }\end{array}$ & $\begin{array}{l}\text { It's anguishing due to the picket fence } \\
\text { effect and spectral leakage and also } \\
\text { sturdily affected due to presence of } \\
\text { noises in the signal. }\end{array}$ \\
\hline 5 & $\begin{array}{l}\text { Gabor-Wigner } \\
\text { Transform }\end{array}$ & $\begin{array}{l}\text { It has good time-frequency resolution } \\
\text { as well as high signal to noise ratio. }\end{array}$ & $\begin{array}{l}\text { The time computational span is on } \\
\text { high complexity as it's directly } \\
\text { associated to sampling frequency. As } \\
\text { well as it has a very limited } \\
\text { availability at high frequencies. }\end{array}$ \\
\hline
\end{tabular}




\section{Classification Techniques of Artificial Intelligence}

Artificial intelligence (AI) can be define as the activities such as detection of a problem then the problem salvation with a valid reason in a keen perception and learning after making a decision that is associate with human thinking is a broad definition defined in [123]. In the recent years, there is enormous research going on to meet the interest of the electric power Community.

\subsection{Classification Based on the Neural Network}

The neural networks (NN) are good at Optimization and data clustering, pattern matching, classification, function approximation. It represents the new era of information processing system [124]. Artificial neural networks function's approximation capabilities were employed in harmonic source classification, faults, and power quality studies. The Time delay neural network (TDNN) and feed-forward neural network (FFNN) are the two different Paradigms of neural networks for the classification of power system disturbance waveforms which are presented in [125]. In [126] Wave-shape fault is displayed for automatic detection, localization and to classify various types of disturbances. In [127] a neural network based approach is proposed to identify the non-intrusive harmonic source. In [128] ANN and Wavelet-based a novel method is proposed for fault detection in line transmission and its classification by using data of oscillographic. Studies are carried out for classification and detection based on some DWT patterns for both high and low-frequency disturbances such as sags, transient, and harmonics, flickers simultaneously in [129]. Power quality disturbances recognition based on wavelet and artificial neural network classifier is tested and implemented in [130]. Feature extraction on center clustering is obtained and fed to the artificial neural network as an input for power quality event classification is presented in [131], while in [132] the author presented a novel method based on $S$ transform and Probabilistic neural network for power quality event classification. In [133] the balanced neutral tree is given by the author for classification of Power quality. To classify and detect single \& combined Power quality disturbance based on a dual neural network based methodology is presented in [134], while in [135] [136] [137] the author introduced the radial basis function (RBF) neural network for classification and recognition of power quality events. In this paper [138] a dual neural network methodology is proposed which detect and classify single and combined power quality which computes the root mean square for harmonic and inter harmonic estimation via an adaptive linear system. In [139] a multilayer perception neural network is presented for classification of power quality. As in most research, the authors used frequency domain as an analysis tool, but in this paper [140] the author presented an approach in the time domain for detection and classification of power quality. In this paper hybrid detection and classification method is shown in which quantity characteristics are introduced then recognition algorithm is used for signal and multiple disturbances recognition [141]. In [142] for real-time power quality evaluation, an artificial neural network is proposed conjugate gradient 
back-propagation. In recent years the latest developments are FPGA based smart sensors which integrate with HOS (higher order statistic) processing cores for analysis of signals which further classify the power quality by artificial neural networks [143].

\subsection{Classification Based on Neuro-Fuzzy System}

The information handling such as imperfect, vague, partial or managed imprecise is one of the biggest advantages of Neuro-fuzzy based methods. It resolves conflicts with capabilities of self-tuning, self-learning, aggregation, self-organizing and collaboration. The operation uses fuzzy numbers for fast computation it doesn't require human imitate decision-making processes or prior knowledge of relationships of data [144] [145]. In [146] the author presented a fuzzy-neutral network as a classifier to extract feature by using morphological filtering and contour extraction while describing a cork stopper, quality classification system principal component analysis along with neuro-fuzzy based automatic classification is presented by four steps algorithm approach with the combination of 3-D space referential representation in [147]. Transmission line faults and its location are proposed via adaptive-neuro-fuzzy-interface system approach in [148] [149]. In [150] the author presented an adaptive neuro-fuzzy system with PSO (Particle-swarm optimization) with phase jumps by UPQC for mitigation of Voltage sags. In this paper [151] FAT (fuzzy assessment tree) supported by SIM HT (short-time modified Hilbert transform) is utilized for detection and classification of multiclass. While low and high limit detection is evaluated against measured data by a fuzzy logic classification system via member functions which are two inputs and one output [152]. Furthermore, in [153] fuzzy logic and ANN for classification of disturbances are s-transform and wavelet such as DTCWT (Dual tree complex wavelet transform).

\subsection{Classification Based on Support Vector Machine}

Vapnik laid the foundation of Support Vector Machine [154]; in this new-fangled pattern recognition is provided by statistical learning theory approach. SVMs belong to the generalized linear combiners which are used for regression and classification via a set of related supervised learning methods [155]. The author presented N-1SVMs' classifier for the identification of PQ event in [156], which works more efficiently in the voltage disturbance via automatic classification [157]. SVM based one-versus-one approach is presented in [158] which can process multiple classifications of Power quality disturbance. The SVM technique is a low convolution event classifier and far better than Optimal time-frequency Representation (OTFR) [159]. In [160] the author presented Wavelet multi-class SVM based an integrated model for recognizing PQ disturbances. In [161] the SVM and DWT combined classifier is shown to recognize the type of Power quality of a system. In the comparison of ANN-based 
methods \& Kamel-based learning method with the direct, a cyclic SVM shows that linear a cyclic SVM have less testing time, less training and with a high degree of accuracy [162]. The power quality events classification based on SVM and wavelet transform is presented in [163] [164] [165]. The modified SVM and TT-transform are used in non-stationary power signals for classification with modified immune optimization algorithm by enhancing the compactness of different clusters of some SVM [166]. The author presented higher order statistical feature along with SVM is used for classification of power quality events in [167]. In this paper the Author presented for the single and multi power quality disturbances a new SVM model which overcomes the limitation of employing a number of binary support vector machines [168]. Where as in [169] the support vector machine as classifier core discriminated the power quality events to perform a satisfactory test in terms of accuracy and speed even in noisy conditions. In [170] the TDR (time-domain reflectometry) technique with PRBS (pseudorandom binary sequence) is used for data set as an appropriate input for PSO based SVM to increase the parameters for classification accuracy. In [171] FIR-DGT and T2FK-SVM is used to enhance the accuracy of classification by reducing the feature size so that less time and memory is required for classification.

\subsection{Classification Based on Genetic Algorithm}

By natural genetics and natural selection mechanism Genetic Algorithm (GA) is a search Algorithm which joins survival of the vigorous among string structures for information exchange with a structured yet randomized to form a search algorithm with some of the innovative flairs of human [172]. It used probabilistic, random, multipoint and guided search mechanism for optimization the GA is considered as one of the intelligent Paradigm [173]. A fuzzy-based adaptive approach is used in [174] to the metering of RMS voltage, power, and current employing GA. In [175] the author presented a validation of power system model for power quality assessment application while using GA. During the dynamic performance of power system, the GA is introduced for monitoring and supervising as a powerful tool [176]. In [177] GA is proposed for the power voltage control optimization system in hierarchical format via a jumping genes paradigm. In [178] the author introduced a new technique while using enhanced GA for placement of Power quality monitors. The extension of GA and wavelet transform is presented in [179] as an analytical technique of power quality. The design of a GA is presented in [180] which optimize the S-transform in perturbation of electrical signals for classification and analysis. In this paper [181] the author presented a model which can perform the disturbance analysis in one step instead of two stages as other types usually do, While in [182] GA is designed as a crossover operator based on particular direction-based.

\subsection{Classification Based on the Fuzzy Expert System}

Classical two-valued logic is a generalized logic system which is referred to fuzzy 
logic in uncertainty for reasoning. It is motivated by the knowledge and concepts which have no defined boundaries but still can be utilized for human reasoning [183]. In [184] [185] the author presented the Mamdani type rules for a fuzzy classification system to evaluate linguistic variable inputs information. In [186] the author presented than a fuzzy expert-system utilizes a collection of fuzzy sets for reasoning about data instead of Boolean sets. A fuzzy set along with wavelet is used by the author to design a tool to quantify Power quality parameters in [187]. While in [188], a fuzzy expert system with linear Kalman filter is used for characterizing power quality events as a hybrid technique. In [189] a particle swarm optimization algorithm along with fuzzy logic approach is for detection \& classification of single and multiple power quality disturbances. Fuzzy clustering using the technique of decision tree and chemo-tactic differential evolution is presented as an approach for the classification of power quality data in [190]. In [191] the author showed a fuzzy expert system based on S transform using power data of quality time series. A variety of window techniques are presented in [192] for various stationary power signals visual localization, detection, and classification. In the electrical system, the transient disturbance classification is proposed in [193] by a using fuzzy expert system with Fourier linear combiner as a hybrid scheme. A wavelet-based extended fuzzy reasoning approach is proposed in [194] for identification a recognition to power quality disturbances, while the abnormal operation of an electrical system is introduced with a technique of an adaptive fuzzy self-learning in [195]. In [196] the author presented a data compression method for a power waveform while using adaptive fuzzy logic. In this paper, the author utilized the MM (mathematical morphology) and FDT (fuzzy decision tree) which is a new contribution to detection and classification [197]. While in [198] [199] [200] the author used different combinations such as automatic, Kalman, Hilbert transforms with a fuzzy expert system for power quality disturbances recognition and classification. In [201] the Author presented a new model which is immune to noise and different which is further modified through Fuzzy C-means based foraging optimization algorithm for improvement in detection and classification.

\subsection{Miscellaneous Classification Systems}

The Important consideration in electric utilities is the detection, and its classification of power quality events. The features of $S$ transform are used to design a Rule-based system for intelligent classification of Power quality disturbances [202] [203]. In [204] the author presented for the classification of power quality events Rule-based wavelet multiresolution decomposition. In this paper [205] by Gaussian window, a simple rule base is created under various non-stationary signal conditions for selecting a suitable window for a reasonable time-frequency localization of the disturbance signal. This rule base uses statistical base entropy measure. Furthermore, in [206] a rule-based method with the help of CS (compressive sensing) and ML (maximum likelihood) are used for classification of 
Power quality disturbances. In [207] [208] the author presented an expert system for the power quality classification. Many other power quality classification methods such as Easy VI program [209] Digital filtering and mathematical morphology [210], Warping Classifier [211], Multi-way principal component analysis [212], Phasor data records and sequence of events [213], inductive inference approach [214], Hardware and software architecture [215] [216] [217], as Hidden Markov models and vector quantization [218], nearest neighbor rule [219], Transient-meter [220], recurrence quantification analysis [221], fault current limiting high-temperature superconductor cable [222] In this paper [223] the two successive stages space and times are achieved by the extension of K-mean algorithm to identify the faults with space-time solution. Furthermore, in [224], a mathematical model is developed for describing waveforms which contains power quality disturbances simultaneously. They have shown significant role in power quality event classification in recent years.

\subsection{Power Quality Events Comparative Cram of Classification Techniques}

A critical review has been carried out of classification methods of power quality events in [123] [224], this comparative study presents the strengths and weakness for different power qualities by various AI techniques are provided in Table 5 to classify and analyzed. While in Table 6 various classification methods for various Power quality disturbances are shown.

\section{Effect of Noise on PQ Event Classifiers}

Noise is the unwanted sound which is accompanied by signals when the monitoring devices captured; it has an adverse effect while extracting relevant features from the signal. Wavelet-based even detection performances are affected more adversely by noises in time localization, event detection and its classification due to the difficulty in separation of noises from the disturbances [225]. In the wavelet-based power quality monitoring system the detection capability is degraded with the presence of noises because when wavelet transform decomposes the power quality data, then multiple frequencies usually reveals at high bands due to noise present in the disturbances. So if compare to the fundamental component the level of noise magnitude is not very high, so it can easily be comparable to disturbance energy at these bands [226]. In [227], the change-point approach is introduced with the help of de-noising technique for monitoring wavelet-based power quality. Consequently, in [228], the author presented a new de-noising technique for the performance improvement of power quality disturbance classification. Power quality events which are influenced with noises can be recognized with the extraction of its integrated features via a neuro-fuzzy network as presented in [229]. Inter-scale \& intra-scale wavelet coefficients dependencies are proposed as a technique to de-noise power quality waveform data to improve time localization and detection of Power quality disturbances in 


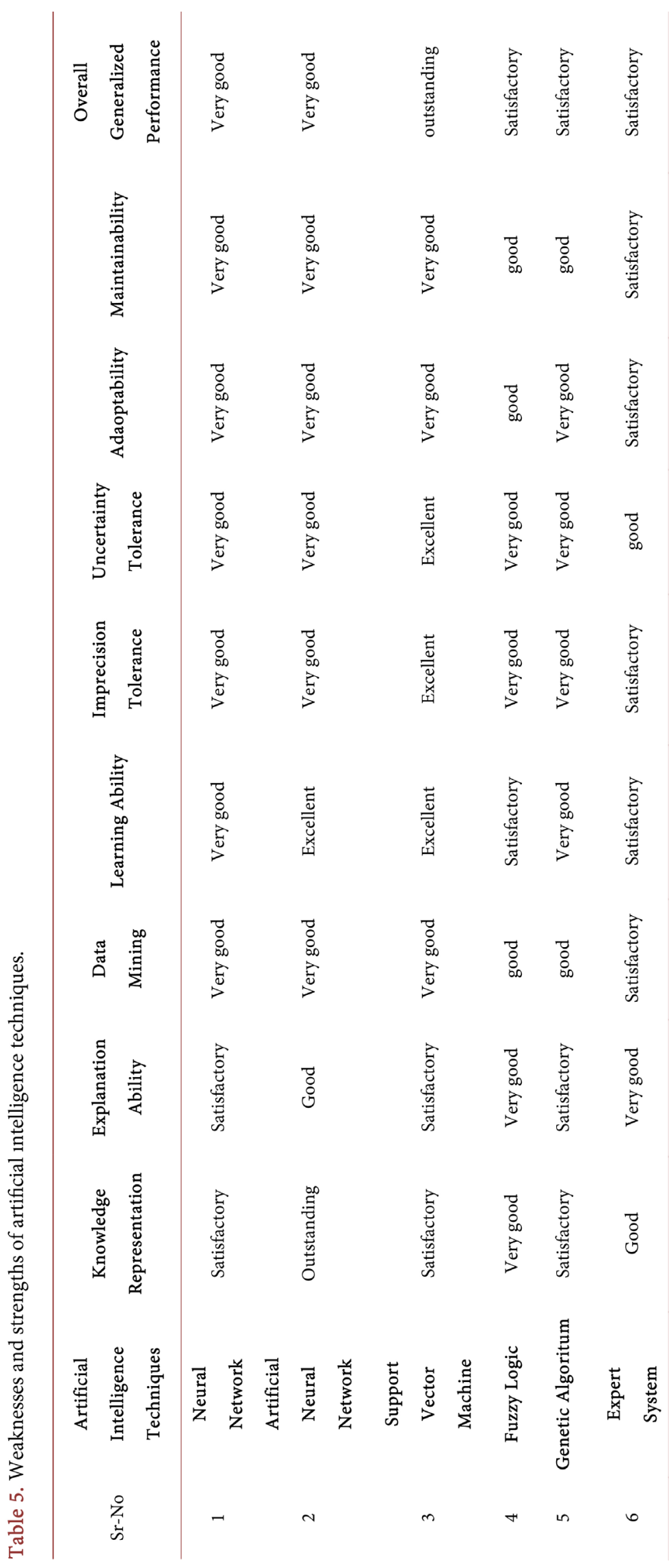


Table 6. Power quality event classification techniques comparison.

\begin{tabular}{|c|c|c|c|}
\hline $\mathrm{Sr}-\mathrm{Nc}$ & $\begin{array}{l}\text { Artificial } \\
\text { o Intelligence } \\
\text { Techniques }\end{array}$ & Advantages & Disadvantages \\
\hline 1 & $\begin{array}{l}\text { Neural } \\
\text { Network }\end{array}$ & $\begin{array}{l}\text { It exhibits high level of accuracy for } \\
\text { diverse and mixed power quality } \\
\text { disturbance classification. }\end{array}$ & $\begin{array}{l}\text { In noisy conditions its efficiency is } \\
\text { very limited or in other words it's less. }\end{array}$ \\
\hline 2 & $\begin{array}{l}\text { Artificial } \\
\text { Neural } \\
\text { Network }\end{array}$ & $\begin{array}{l}\text { It offers mathematical suppleness } \\
\text { with high accuracy in real time } \\
\text { applications. }\end{array}$ & $\begin{array}{l}\text { Its accuracy and convergence depends } \\
\text { on its network architecture and also } \\
\text { dependent on noises in the signal. }\end{array}$ \\
\hline 3 & $\begin{array}{l}\text { Support } \\
\text { Vector } \\
\text { Machine }\end{array}$ & $\begin{array}{l}\text { It has a high learning process with a } \\
\text { prospective to grip hefty features; it } \\
\text { also provides a stable solution in } \\
\text { quadratic optimization. }\end{array}$ & $\begin{array}{l}\text { Its total dependent on training } \\
\text { samples if they are minimum, the } \\
\text { classification accuracy is poor and vice } \\
\text { versa. }\end{array}$ \\
\hline 4 & Fuzzy Logic & $\begin{array}{l}\text { It has a fascinated accuracy in } \\
\text { analyzing complex systems and it's } \\
\text { accurate in modeling. }\end{array}$ & $\begin{array}{l}\text { It cannot accommodate new } \\
\text { disturbances as its training set is } \\
\text { limited for every case. }\end{array}$ \\
\hline 5 & $\begin{array}{l}\text { Genetic } \\
\text { Algorithm }\end{array}$ & $\begin{array}{l}\text { It classifies accurately power quality } \\
\text { disturbances which are generated due } \\
\text { to damped sub harmonic signals and } \\
\text { dynamic performance of the power } \\
\text { system. }\end{array}$ & It has a very high computational time. \\
\hline 6 & $\begin{array}{l}\text { Expert } \\
\text { System }\end{array}$ & $\begin{array}{l}\text { It has the facility that it can be used } \\
\text { with/without limited data. }\end{array}$ & $\begin{array}{l}\text { In this, the actual situation and } \\
\text { assumptions do not match exactly and } \\
\text { the extract of conclusion is very } \\
\text { difficult furthermore its execution is } \\
\text { very slow, moreover the system is very } \\
\text { expensive. }\end{array}$ \\
\hline
\end{tabular}

[230], which is simple but yet effective de-noising method. In [231] wavelet-based Power quality monitoring is proposed a method of spatial noise-suppression as a de-noising technique. In this paper [232] the proposed is a quantile smoothing techniques to noisy signal, while in [233] the EMD based method for de-noising is proposed to align common frequency through multiple channels for facilitating the de-noising data. Furthermore [234] suggest the algorithm to the complex-valued differential for signal separation problems. The usage of SVM and ANN for the classification of power quality due to the presence of noise is presented in Table 7 as a brief comparative study.

\section{The Prospect Possibility}

The future major thrust is in four aspects, Economical, Fast \& Accurate, Secure \& Reliable and Miniature \& Safe while the Present thrust in Power quality is real-time analysis, many scientists and researchers work day and night for the mitigation and enhancement of real-time power quality detection. The new era needs new techniques out of the box which can work on real-time power quality events for mitigation ad classification. In other words, the standards are still far 
Table 7. The noise effect on the classification techniques of power quality.

\begin{tabular}{ccccccc}
\hline Sr. No & $\begin{array}{c}\text { Power Quality } \\
\text { Classification } \\
\text { Techniques }\end{array}$ & Notch & Transients & Voltage-Sag & Voltage-Swell & $\begin{array}{c}\text { Sinusoidal } \\
\text { Waveform }\end{array}$ \\
\hline 1 & SVM & 3.74 & 4.69 & 4.63 & 5.65 & 8.87 \\
2 & ANN & 3.24 & 5.47 & 7.49 & 7.49 & 9.66 \\
\hline
\end{tabular}

away from the targeted standards as the power system is expanding day by day with numerous \& anonymous power devices which generate an advance version of Power quality errors which are still to discover. Single and multiple Power quality errors need a generalized approach for detection and classification. On the basis, it is possible that blackout conditions can be improved.

\section{Conclusion}

Detection and classification are two of the key aspects of the electrical power system on which this comprehensive and critical literature review is carried out. All recent publications on detection and classification are presented in this paper; the literature survey uses detection/feature extraction methods such as Fourier transform, S-transform, wavelet transform, Hilbert-Huang transform and artificial intelligence methods for power quality classification such as artificial neural network, SVM, GA and fuzzy logic. It also includes the classification power quality events effect due to different types of noises. Furthermore, in the end, the future research scope is indicated in the field of power quality and classification methods. As per developed review most commonly used methods for power quality disturbances are HHT, FT, ST, and WT while regarding event classification the commonly used algorithm trend is based on SVM, ANN, FS, ES, and GA. The compressive review literature will help authors for selecting the particular method/techniques for their specific application/task and as well as the effectiveness of the particular methods with their significant advantages and disadvantages as outlined.

\section{Conflicts of Interest}

The authors declare no conflicts of interest regarding the publication of this paper.

\section{References}

[1] Thapar, A., Saha, T.K. and Dong, Z.Y. (2004) Investigation of Power Quality Categorization and Simulating Its Impact on Sensitive Electronic Equipment. IEEE Power Engineering Society General Meeting, Denver, 6-10 June 2004, 528-533.

[2] Smith, J.C., Hensley, G. and Ray, L. (1995) 1159-1995-IEEE Recommended Practice for Monitoring Electric Power Quality. IEEE, New York.

[3] Montoya, F.G., García-Cruz, A., Montoya, M.G. and Manzano-Agugliaro, F. (2016) Power Quality Techniques Research Worldwide: A Review. Renewable and Sustainable Energy Reviews, 54, 846-856. https://doi.org/10.1016/j.rser.2015.10.091 
[4] Liang, X. (2017) Emerging Power Quality Challenges Due to the Integration of Renewable Energy Sources. IEEE Transactions on Industry Applications, 53, 855-866. https://doi.org/10.1109/TIA.2016.2626253

[5] Dugan, R.C., McGranaghan, M.F. and Beaty, H.W. (1996) Electrical Power Systems Quality. McGraw-Hill, New York.

[6] Flores, R.A. (2002) State of the Art in the Classification of Power Quality Events, an Overview. 10th International Conference on Harmonics and Quality of Power, Rio de Janeiro, 6-9 October 2002, 17-20. https://doi.org/10.1109/ICHQP.2002.1221398

[7] Brenna, M., Faranda, R. and Tironi, E. (2009) A New Proposal for Power Quality and Custom Power Improvement: OPEN UPQC. IEEE Transactions on Power Delivery, 24, 2107-2116. https://doi.org/10.1109/TPWRD.2009.2028791

[8] Morales-Velazquez, L., de Jesus Romero-Troncoso, R., Herrera-Ruiz, G., Morinigo-Sotelo, D. and Osornio-Rios, R.A. (2017) Smart Sensor Network for Power Quality Monitoring in Electrical Installations. Measurement, 103, 133-142. https://doi.org/10.1016/j.measurement.2017.02.032

[9] Teke, A., Saribulut, L. and Tumay, M. (2011) A Novel Reference Signal Generation Method for Power-Quality Improvement of Unified Power-Quality Conditioner. IEEE Transactions on Power Delivery, 26, 2205-2214. https://doi.org/10.1109/TPWRD.2011.2141154

[10] Sharon, D., Montano, J.C., Lopez, A., Castilla, M., Borras, D. and Gutiérrez, J. (2008) Power Quality Factor for Networks Supplying Unbalanced Nonlinear Loads. IEEE Transactions on Instrumentation and Measurement, 57, 1268-1274. https://doi.org/10.1109/TIM.2007.915146

[11] Biswal, B., Dash, P.K. and Mishra, S. (2011) A Hybrid Ant Colony Optimization Technique for Power Signal Pattern Classification. Expert Systems with Applications, 38, 6368-6375. https://doi.org/10.1016/j.eswa.2010.11.102

[12] Kwan, K.H., So, P.L. and Chu, Y.C. (2012) An Output Regulation-Based Unified Power Quality Conditioner with Kalman Filters. IEEE Transactions on Industrial Electronics, 59, 4248-4262. https://doi.org/10.1109/TIE.2012.2193852

[13] Rajasekaran, J. and Sasiraja, R.M. (2012) An Output Regulation-Based Unified Power Quality Conditioner with Kalman Filter. International Journal of Engineering Trends and Technology, 1, 3012-3019.

[14] Wang, X., Yong, J., Xu, W. and Freitas, W. (2011) Practical Power Quality Charts for Motor Starting Assessment. IEEE Transactions on Power Delivery, 26, 799-808. https://doi.org/10.1109/TPWRD.2010.2096237

[15] Zhang, M., Li, K. and Hu, Y. (2011) A Real-Time Classification Method of Power Quality Disturbances. Electric Power Systems Research, 81, 660-666. https://doi.org/10.1016/j.epsr.2010.10.032

[16] Ken, D. and Hedman, H. (2005) The Role of Distributed Generation in Power Quality and Reliability: Final Report. Energy and Environmental Analysis.

[17] Kezunovic, M. and Liao, Y. (2002) A Novel Software Implementation Concept for Power Quality Study. IEEE Transactions on Power Delivery, 17, 544-549. https://doi.org/10.1109/61.997935

[18] Dugan, R.C. and McGranaghan, M.F. (2002) Electrical Power Systems Quality. 2nd Edition, McGraw-Hill, New York.

[19] Monedero, I., Leon, C., Ropero, J., Garcia, A., Elena, J.M. and Montano, J.C. (2007) Classification of Electrical Disturbances in Real Time Using Neural Networks. IEEE Transactions on Power Delivery, 22, 1288-1296. https://doi.org/10.1109/TPWRD.2007.899522 
[20] Willems, J.L., Ghijselen, J.A. and Emanuel, A.E. (2005) The Apparent Power Concept and the IEEE Standard 1459-2000. IEEE Transactions on Power Delivery, 20, 876-884. https://doi.org/10.1109/TPWRD.2005.844267

[21] Filipski, P.S., Baghzouz, Y. and Cox, M.D. (1994) Discussion of Power Definitions Contained in the IEEE Dictionary. IEEE Transactions on Power Delivery, 9, 1237-1244. https://doi.org/10.1109/61.311149

[22] Alfonso-Gil, J.C., Orts-Grau, S., Munoz-Galeano, N., Gimeno-Sales, F.J. and Segui-Chilet, S. (2013) A Measurement System for a Power Quality Improvement Structure Based on IEEE Std. 1459. IEEE Transactions on Instrumentation and Measurement, 62, 3177-3188. https://doi.org/10.1109/TIM.2013.2270901

[23] IEEE (2010) 1459-2010-IEEE Standard Definitions for the Measurement of Electric Power Quantities under Sinusoidal, Non-Sinusoidal, Balanced, or Unbalanced Conditions. IEEE, New York.

[24] Ferreira, S.C., Gonzatti, R.B., da Silva, C.H., Pereira, R.R., da Silva, L.E.B., Lambert-Torres, G. and Ahn, S.U. (2011) An Adaptive Algorithm for Real-Time Power Quality Measurement According to IEEE Std. 1459-2000. XI Brazilian Power Electronics Conference, Praiamar, 11-15 September 2011, 249-255. https://doi.org/10.1109/COBEP.2011.6085257

[25] Saxena, D., Verma, K. and Singh, S. (2010) Power Quality Event Classification: An Overview and Key Issues. International Journal of Engineering, Science, and Technology, 2, 186-199. https://doi.org/10.4314/ijest.v2i3.59190

[26] Barros, J., Diego, R.I. and De Apráiz, M. (2012) Applications of Wavelets in Electric Power Quality: Voltage Events. Electric Power Systems Research, 88, 130-136. https://doi.org/10.1016/j.epsr.2012.02.009

[27] Bollen, M.H. and Gu, I. (2006) Signal Processing of Power Quality Disturbances (Vol. 30). John Wiley \& Sons, New York. https://doi.org/10.1002/0471931314

[28] Gunal, S., Gerek, O.N., Ece, D.G. and Edizkan, R. (2009) The Search for the Optimal Feature Set in Power Quality Event Classification. Expert Systems with Applications, 36, 10266-10273. https://doi.org/10.1016/j.eswa.2009.01.051

[29] Ribeiro, M.V., Romano, J.M. and Duque, C.A. (2004) An Improved Method for Signal Processing and Compression in Power Quality Evaluation. IEEE transactions on Power Delivery, 19, 464-471. https://doi.org/10.1109/TPWRD.2003.822497

[30] Sethi, S. and Upadhyay, R. (2017) Classification of Mental Tasks Using S-Transform Based Fractal Features. 2017 International Conference on Computer, Communications, and Electronics, Jaipur, 1-2 July 2017, 38-43. https://doi.org/10.1109/COMPTELIX.2017.8003934

[31] Ji, T.Y., Wu, Q.H., Jiang, L. and Tang, W.H. (2011) Disturbance Detection, Location, and Classification in Phase Space. IET Generation, Transmission \& Distribution, 5, 257-265. https://doi.org/10.1049/iet-gtd.2010.0254

[32] Yang, L., Yu, J. and Lai, Y. (2010) Disturbance Source Identification of Voltage Sags Based on Hilbert-Huang Transform. 2010 Asia-Pacific Power and Energy Engineering Conference, Chengdu, 28-31 March 2010, 1-4. https://doi.org/10.1109/APPEEC.2010.5448916

[33] Rilling, G., Flandrin, P. and Goncalves, P. (2003) On Empirical Mode Decomposition and Its Algorithms. IEEE-EURASIP Workshop on Nonlinear Signal and Image Processing, 3, 8-11.

[34] Afroni, M.J., Sutanto, D. and Stirling, D. (2013) Analysis of Nonstationary Power-Quality Waveforms Using Iterative Hilbert Huang Transform and SAX Algorithm. IEEE Transactions on Power Delivery, 28, 2134-2144. 
https://doi.org/10.1109/TPWRD.2013.2264948

[35] Huang, N.E., et al. (1998) The Empirical Mode Decomposition and the Hilbert Spectrum for Nonlinear and Non-Stationary Time Series Analysis. Proceedings of the Royal Society, 454, 903-995. https://doi.org/10.1098/rspa.1998.0193

[36] Shukla, S., Mishra, S. and Singh, B. (2009) Empirical-Mode Decomposition with Hilbert Transforms for Power-Quality Assessment. IEEE Transactions on Power Delivery, 24, 2159-2165. https://doi.org/10.1109/TPWRD.2009.2028792

[37] Hafiz, F., Chowdhury, A.H. and Shahnaz, C. (2012) An Approach for Classification of Power Quality Disturbances Based on Hilbert Huang Transform and Relevance Vector Machine. 20127 th International Conference on Electrical \& Computer Engineering, Dhaka, 20-22 December 2012, 201-204.

https://doi.org/10.1109/ICECE.2012.6471520

[38] Wang, Z., Zeng, X.J., Hu, X.X. and Hu, J.Y. (2012) The Multi-Disturbance Complex Power Quality Signal HHT Detection Technique. IEEE PES Innovative Smart Grid Technologies, Tianjin, 21-24 May 2012, 1-5. https://doi.org/10.1109/ISGT-Asia.2012.6303259

[39] Önal, Y. and Turhal, Ü.Ç. (2013) The Orthogonal Hilbert-Huang Transform Application in Voltage Flicker Analysis. 4th International Conference on Power Engineering, Energy and Electrical Drives, Istanbul, 13-17 May 2013, 700-704. https://doi.org/10.1109/PowerEng.2013.6635695

[40] Huang, Y., Liu, Y. and Hong, Z. (2009) Detection and Location of Power Quality Disturbances Based on Mathematical Morphology and Hilbert-Huang Transform. 2009 9th International Conference on Electronic Measurement \& Instruments, Beijing, 16-19 August 2009, 2-319. https://doi.org/10.1109/ICEMI.2009.5274596

[41] Senroy, N., Suryanarayanan, S. and Ribeiro, P.F. (2007) An Improved Hilbert-Huang Method for Analysis of Time-Varying Waveforms in Power Quality. IEEE Transactions on Power Systems, 22, 1843-1850. https://doi.org/10.1109/TPWRS.2007.907542

[42] Jayasree, T., Devaraj, D. and Sukanesh, R. (2010) Power Quality Disturbance Classification Using Hilbert Transform and RBF Networks. Neurocomputing, 73, 1451-1456. https://doi.org/10.1016/j.neucom.2009.11.008

[43] Rodriguez, A., Ruiz, I.E., Aguado, J., Lopez, J.J., Martin, F.I. and Muñoz, F. (2011) Classification of Power Quality Disturbances Using S-Transform and Artificial Neural Networks. 2011 International Conference on Power Engineering, Energy and Electrical Drives, Malaga, 11-13 May 2011, 1-6. https://doi.org/10.1109/PowerEng.2011.6036517

[44] Dash, P.K., Panigrahi, B.K. and Panda, G. (2003) Power Quality Analysis Using S-Transform. IEEE Transactions on Power Delivery, 18, 406-411. https://doi.org/10.1109/TPWRD.2003.809616

[45] Bhuiyan, M.J.U., Begum, M.T.A. and Alam, M.R. (2017) S-Transform and Mahalanobis Distance-Based Approach for Classifying Power Quality Disturbances. International Conference on Electrical, Computer and Communication Engineering, Cox's Bazar, 16-18 February 2017, 681-685.

[46] Suja, S. and Jerome, J. (2010) Pattern Recognition of Power Signal Disturbances Using S Transform and TT Transform. International Journal of Electrical Power \& Energy Systems, 32, 37-53. https://doi.org/10.1016/j.ijepes.2009.06.012

[47] Li, J., Teng, Z., Tang, Q. and Song, J. (2016) Detection and Classification of Power Quality Disturbances Using Double Resolution S-Transform and DAG-SVMs. IEEE Transactions on Instrumentation and Measurement, 65, 2302-2312. 
https://doi.org/10.1109/TIM.2016.2578518

[48] Zhao, F. and Yang, R. (2007) Power-Quality Disturbance Recognition Using S-Transform. IEEE Transactions on Power Delivery, 22, 944-950. https://doi.org/10.1109/TPWRD.2006.881575

[49] He, S., Li, K. and Zhang, M. (2013) A Real-Time Power Quality Disturbances Classification Using a Hybrid Method Based on S-Transform and Dynamics. IEEE Transactions on Instrumentation and Measurement, 62, 2465-2475. https://doi.org/10.1109/TIM.2013.2258761

[50] Uyar, M., Yildirim, S. and Gencoglu, M.T. (2009) An Expert System Based on S-Transform and Neural Network for Automatic Classification of Power Quality Disturbances. Expert Systems with Applications, 36, 5962-5975. https://doi.org/10.1016/j.eswa.2008.07.030

[51] Reddy, M.J.B., Raghupathy, R.K., Venkatesh, K.P. and Mohanta, D.K. (2013) Power Quality Analysis Using Discrete Orthogonal S-Transform (DOST). Digital Signal Processing, 23, 616-626. https://doi.org/10.1016/j.dsp.2012.09.013

[52] Chilukuri, M.V. and Dash, P.K. (2004) Multiresolution S-Transform-Based Fuzzy Recognition System for Power Quality Events. IEEE Transactions on Power Delivery, 19, 323-330. https://doi.org/10.1109/TPWRD.2003.820180

[53] Biswal, M. and Dash, P.K. (2013) Detection and Characterization of Multiple Power Quality Disturbances with a Fast S-Transform and Decision Tree Based Classifier. Digital Signal Processing, 23, 1071-1083. https://doi.org/10.1016/j.dsp.2013.02.012

[54] Mahela, O.P. and Shaik, A.G. (2016) Recognition of Power Quality Disturbances Using S-Transform and Fuzzy C-Means Clustering. 2016 International Conference on Cogeneration, Small Power Plants and District Energy, Bangkok, 14-16 September 2016, 1-6. https://doi.org/10.1109/COGEN.2016.7728955

[55] Kumar, R., Singh, B., Shahani, D.T., Chandra, A. and Al-Haddad, K. (2015) Recognition of Power-Quality Disturbances Using S-Transform-Based ANN Classifier and rule-Based Decision Tree. IEEE Transactions on Industry Applications, 51, 1249-1258. https://doi.org/10.1109/TIA.2014.2356639

[56] Mahela, O.P. and Shaik, A.G. (2016) Recognition of Power Quality Disturbances Using S-Transform and Rule-Based Decision Tree. 2016 IEEE 1st International Conference on Power Electronics, Intelligent Control and Energy Systems, Delhi, 4-6 Julyr 2016, 1-6. https://doi.org/10.1109/ICPEICES.2016.7853093

[57] Santoso, S., Powers, E.J., Grady, W.M. and Hofmann, P. (1996) Power Quality Assessment via Wavelet Transform Analysis. IEEE Transactions on Power Delivery, 11, 924-930. https://doi.org/10.1109/61.489353

[58] Santoso, S., Powers, E.J. and Grady, W.M. (1997) Power Quality Disturbance Data Compression Using Wavelet Transform Methods. IEEE Transactions on Power Delivery, 12, 1250-1257. https://doi.org/10.1109/61.637001

[59] Angrisani, L., Daponte, P., D’apuzzo, M. and Testa, A. (1998). A Measurement Method Based on the Wavelet Transform for Power Quality Analysis. IEEE Transactions on Power Delivery, 13, 990-998. https://doi.org/10.1109/61.714415

[60] Sharma, A.K., Mahela, O.P. and Ola, S.R. (2016) Detection of Power Quality Disturbances Using Discrete Wavelet Transform. 18th International Conference on Electrical Power and Energy Systems, Los Angeles, 5-6 April 2016, 450-455.

[61] Gaouda, A.M., Salama, M.M.A., Sultan, M.R. and Chikhani, A.Y. (1999) Power Quality Detection and Classification Using Wavelet-Multiresolution Signal Decomposition. IEEE Transactions on Power Delivery, 14, 1469-1476. https://doi.org/10.1109/61.796242 
[62] Chen, X.X. (2002) Wavelet-Based Detection, Localization, Quantification and Classification of Short Duration Power Quality Disturbances. 2002 IEEE Power Engineering Society Winter Meeting. Conference Proceedings, New York, 27-31 January 2002, 931-936.

[63] Hamid, E.Y. and Kawasaki, Z.I. (2002) Wavelet-Based Data Compression of Power System Disturbances Using the Minimum Description Length Criterion. IEEE Transactions on Power Delivery, 17, 460-466. https://doi.org/10.1109/61.997918

[64] Lin, C.H. and Tsao, M.C. (2005) Power Quality Detection with Classification Enhancive Wavelet-Probabilistic Network in a Power System. IEE Proceedings-Generation, Transmission, and Distribution, 152, 969-976. https://doi.org/10.1049/ip-gtd:20045177

[65] He, H. and Starzyk, J.A. (2006) A Self-Organizing Learning Array System for Power Quality Classification Based on Wavelet Transform. IEEE Transactions on Power Delivery, 21, 286-295. https://doi.org/10.1109/TPWRD.2005.852392

[66] Morsi, W.G. and \& El-Hawary, M.E. (2008) A New Perspective for the IEEE Standard 1459-2000 via Stationary Wavelet Transforms in the Presence of Nonstationary Power Quality Disturbance. IEEE Transactions on Power Delivery, 23, 2356-2365. https://doi.org/10.1109/TPWRD.2008.2002660

[67] Morsi, W.G. and El-Hawary, M.E. (2009) Wavelet Packet Transform-Based Power Quality Indices for Balanced and Unbalanced Three-Phase Systems under Stationary or Nonstationary Operating Conditions. IEEE Transactions on Power Delivery, 24, 2300-2310. https://doi.org/10.1109/TPWRD.2009.2027496

[68] Langella, R., Testa, A. and Et, A. (2014) 591-2014-IEEE Recommended Practice and Requirements for Harmonic Control in Electric Power Systems. IEEE, New York.

[69] IEEE (2000) 1459-2000-IEEE Standard Definitions for the Measurement of Electric Quantities under Sinusoidal, Nonsinusoidal, Balanced, or Unbalanced Conditions. IEEE, New York.

[70] Uyar, M., Yildirim, S. and Gencoglu, M.T. (2008) An Effective Wavelet-Based Feature Extraction Method for Classification of Power Quality Disturbance Signals. Electric Power Systems Research, 78, 1747-1755.

https://doi.org/10.1016/j.epsr.2008.03.002

[71] Ray, P.K., Mohanty, S.R. and Kishor, N. (2011) Disturbance Detection in Grid-Connected Distributed Generation System Using Wavelet and S-Transform. Electric Power Systems Research, 81, 805-819. https://doi.org/10.1016/j.epsr.2010.11.011

[72] Zafar, T. and Morsi, W.G. (2013) Power Quality and the Un-Decimated Wavelet Transform: An Analytic Approach for Time-Varying Disturbances. Electric Power Systems Research, 96, 201-210. https://doi.org/10.1016/j.epsr.2012.11.016

[73] Khokhar, S., Zin, A.A.M., Memon, A.P. and Mokhtar, A.S. (2017) A New Optimal Feature Selection Algorithm for Classification of Power Quality Disturbances Using Discrete Wavelet Transform and Probabilistic Neural Network. Measurement, 95, 246-259. https://doi.org/10.1016/j.measurement.2016.10.013

[74] Thirumala, K., Maganuru, S.P., Jain, T. and Umarikar, A. (2016) Tunable-Q Wavelet Transform and Dual Multiclass SVM for Online Automatic Detection of Power Quality Disturbances. IEEE Transactions on Smart Grid, 9, 3018-3028. https://doi.org/10.1109/TSG.2016.2624313

[75] Malbasa, V., Zheng, C., Chen, P.C., Popovic, T. and Kezunovic, M. (2017) Voltage Stability Prediction Using Active Machine Learning. IEEE Transactions on Smart Grid, 8, 3117-3124. https://doi.org/10.1109/TSG.2017.2693394 
[76] De Yong, D., Bhowmik, S. and Magnago, F. (2015) An Effective Power Quality Classifier Using Wavelet Transform and Support Vector Machines. Expert Systems with Applications, 42, 6075-6081. https://doi.org/10.1016/j.eswa.2015.04.002

[77] Uçar, F., Alçin, Ö.F., Dandil, B. and Ata, F. (2016) Machine Learning Based Power Quality Event Classification Using Wavelet-Entropy and Basic Statistical Features. 201621 st International Conference on Methods and Models in Automation and Robotics, Miedzyzdroje, 29 August-1 September 2016, 414-419. https://doi.org/10.1109/MMAR.2016.7575171

[78] Sahani, M., Mishra, S., Ipsita, A. and Upadhyay, B. (2016) Detection and Classification of Power Quality Event Using Wavelet Transform and Weighted Extreme Learning Machine. 2016 International Conference on Circuit, Power and Computing Technologies, Nagercoil, 18-19 March 2016, 1-6.

[79] Markovska, M. and Taskovski, D. (2017) On the Choice of Wavelet-Based Features in Power Quality Disturbances Classification. 2017 IEEE International Conference on Environment and Electrical Engineering and 2017 IEEE Industrial and Commercial Power Systems Europe, Milan, 6-9 June, 2017, 1-6. https://doi.org/10.1109/EEEIC.2017.7977586

[80] Naik, C., Hafiz, F., Swain, A. and Kar, A.K. (2016) Classification of Power Quality Events Using Wavelet Packet Transform and extreme Learning Machine. IEEE Annual Southern Power Electronics Conference, Auckland, 5-8 December 2016, 1-6. https://doi.org/10.1109/SPEC.2016.7846169

[81] Upadhyaya, S. and Mohanty, S. (2016) Localization and Classification of Power Quality Disturbances using Maximal Overlap Discrete Wavelet Transform and Data Mining Based Classifiers**Sponsor, and Financial Support Acknowledgment Goes here. Paper Titles Should Be Written in Uppercase and Lowercase Letters, Not All Uppercase. IFAC-PapersOnLine, 49, 437-442.

https://doi.org/10.1016/j.ifacol.2016.03.093

[82] Deokar, S.A. and Waghmare, L.M. (2014) Integrated DWT-FFT Approach for Detection and Classification of Power Quality Disturbances. International Journal of Electrical Power \& Energy Systems, 61, 594-605. https://doi.org/10.1016/j.ijepes.2014.04.015

[83] Kamthekar, P.R., Munje, R.K. and Kushare, B.E. (2017) Detection and Classification of Power Quality Events Using DWT and MSD. 2017 International Conference on Innovative Mechanisms for Industry Applications, Bengaluru, 21-23 February 2017, 150-157. https://doi.org/10.1109/ICIMIA.2017.7975591

[84] Karimi, M., Mokhtari, H. and Iravani, M.R. (2000) Wavelet-Based On-Line Disturbance Detection for Power Quality Applications. IEEE Transactions on Power Delivery, 15, 1212-1220. https://doi.org/10.1109/61.891505

[85] Axelberg, P.G., Gu, I.Y.H. and Bollen, M.H. (2007) Support Vector Machine for Classification of Voltage Disturbances. IEEE Transactions on Power Delivery, 22, 1297-1303. https://doi.org/10.1109/TPWRD.2007.900065

[86] Granados-Lieberman, D., Romero-Troncoso, R.J., Osornio-Rios, R.A., Garcia-Perez, A. and Cabal-Yepez, E. (2011) Techniques and Methodologies for Power Quality Analysis and Disturbances Classification in Power Systems: A Review. IET Generation, Transmission \& Distribution, 5, 519-529.

https://doi.org/10.1049/iet-gtd.2010.0466

[87] Dash, P.K., Panigrahi, B.K., Sahoo, D.K. and Panda, G. (2003) Power Quality Disturbance Data Compression, Detection, and Classification Using Integrated Spline Wavelet and S-Transform. IEEE Transactions on Power Delivery, 18, 595-600. https://doi.org/10.1109/TPWRD.2002.803824 
[88] Lee, I.W. and Dash, P.K. (2003) S-Transform-Based Intelligent System for Classification of Power Quality Disturbance Signals. IEEE Transactions on Industrial Electronics, 50, 800-805. https://doi.org/10.1109/TIE.2003.814991

[89] Gu, Y.H. and Bollen, M.H. (2000) Time-Frequency and Time-Scale Domain Analysis of Voltage Disturbances. IEEE Transactions on Power Delivery, 15, 1279-1284. https://doi.org/10.1109/61.891515

[90] Wright, P.S. (1999) Short-Time Fourier Transforms and Wigner-Ville Distributions Applied to the Calibration of Power Frequency Harmonic Analyzers. IEEE Transactions on Instrumentation and Measurement, 48, 475-478. https://doi.org/10.1109/19.769633

[91] Jurado, F. and Saenz, J.R. (2002) Comparison between Discrete STFT and Wavelets for the Analysis of Power Quality Events. Electric Power Systems Research, 62, 183-190. https://doi.org/10.1016/S0378-7796(02)00035-4

[92] Huang, S.J., Hsieh, C.T. and Huang, C.L. (1999) Application of Morlet Wavelets to Supervise Power System Disturbances. IEEE Transactions on Power Delivery, 14, 235-243. https://doi.org/10.1109/61.736728

[93] Santoso, S., Grady, W.M., Powers, E.J., Lamoree, J. and Bhatt, S.C. (2000) Characterization of Distribution Power Quality Events with Fourier and Wavelet Transforms. IEEE Transactions on Power Delivery, 15, 247-254. https://doi.org/10.1109/61.847259

[94] Heydt, G.T., Fjeld, P.S., Liu, C.C., Pierce, D., Tu, L. and Hensley, G. (1999) Applications of the Windowed FFT to Electric Power Quality Assessment. IEEE Transactions on Power Delivery, 14, 1411-1416. https://doi.org/10.1109/61.796235

[95] Islam, M.M., Hossain, M.R., Dougal, R.A. and Brice, C.W. (2016) Analysis of Real-World Power Quality Disturbances Employing Time-Frequency Distribution. 2016 Clemson University Power Systems Conference, Clemson, 8-11 March 2016, 1-5. https://doi.org/10.1109/PSC.2016.7462816

[96] Borges, F.A., Fernandes, R.A., Silva, I.N. and Silva, C.B. (2016) Feature Extraction and Power Quality Disturbances Classification Using Smart Meters Signals. IEEE Transactions on Industrial Informatics, 12, 824-833. https://doi.org/10.1109/TII.2015.2486379

[97] Lin, L., Wu, X., Qi, J. and Ci, H. (2016) Power Quality Disturbance Classification Based on a Novel Fourier Neural Network and Hyperbolic S-Transform. International Journal of Signal Processing, Image Processing, and Pattern Recognition, 9, 111-124. https://doi.org/10.14257/ijsip.2016.9.1.11

[98] Singh, U. and Singh, S.N. (2017) Application of Fractional Fourier Transforms for Classification of Power Quality Disturbances. IET Science, Measurement \& Technology, 11, 67-76. https://doi.org/10.1049/iet-smt.2016.0194

[99] Dwivedi, U.D. and Singh, S.N. (2009) Denoising Techniques with a Change-Point Approach for Wavelet-Based Power-Quality Monitoring. IEEE Transactions on Power Delivery, 24, 1719-1727. https://doi.org/10.1109/TPWRD.2009.2022665

[100] Krishna, B.V. and Baskaran, K. (2013) Parallel Computing for Efficient Time-Frequency Feature Extraction of Power Quality Disturbances. IET Signal Processing, 7, 312-326. https://doi.org/10.1049/iet-spr.2012.0262

[101] Norman, C.F., Chan, J.Y., Lau, W.H. and Lai, L.L. (2012) Hybrid Wavelet and Hilbert Transform with Frequency-Shifting Decomposition for Power Quality Analysis. IEEE Transactions on Instrumentation and Measurement, 61, 3225-3233. https://doi.org/10.1109/TIM.2012.2211474

[102] Zhang, H., Liu, P. and Malik, O.P. (2003) Detection and Classification of Power 
Quality Disturbances in Noisy Conditions. IEE Proceedings-Generation, Transmission, and Distribution, 150, 567-572. https://doi.org/10.1049/ip-gtd:20030459

[103] Lin, W.M. Wu, C.H. Lin, C.H. and Cheng, F.S. (2008) Detection and Classification of Multiple Power-Quality Disturbances with Wavelet Multiclass SVM. IEEE Transactions on Power Delivery, 23, 2575-2582. https://doi.org/10.1109/TPWRD.2008.923463

[104] Dash, P.K., Liew, A.C., Salama, M.M.A., Mishra, B.R. and Jena, R.K. (1999) A New Approach to Identification of Transient Power Quality Problems Using Linear Combiners. Electric Power Systems Research, 51, 1-11. https://doi.org/10.1016/S0378-7796(98)00087-X

[105] Abdel-Galil, T.K., El-Saadany, E.F. and Salama, M.M.A. (2003) Power Quality Event Detection Using Adaline. Electric Power Systems Research, 64, 137-144. https://doi.org/10.1016/S0378-7796(02)00173-6

[106] Chen, Z. and Urwin, P. (2001) Power Quality Detection and Classification Using Digital Filters. 2001 IEEE Porto Power Tech Proceedings, Porto, 10-13 September 2001, 1-6. https://doi.org/10.1109/PTC.2001.964610

[107] Yilmaz, A.S., Alkan, A. and Asyali, M.H. (2008) Applications of Parametric Spectral Estimation Methods on Detection of Power System Harmonics. Electric Power Systems Research, 78, 683-693. https://doi.org/10.1016/j.epsr.2007.05.011

[108] Cho, S.H., Jang, G. and Kwon, S.H. (2010) Time-Frequency Analysis of Power-Quality Disturbances via the Gabor-Wigner Transform. IEEE Transactions on Power Delivery, 25, 494-499. https://doi.org/10.1109/TPWRD.2009.2034832

[109] Decanini, J.G., Tonelli-Neto, M.S., Malange, F.C. and Minussi, C.R. (2011) Detection and Classification of Voltage Disturbances Using a Fuzzy-ARTMAP-Wavelet Network. Electric Power Systems Research, 81, 2057-2065. https://doi.org/10.1016/j.epsr.2011.07.018

[110] Styvaktakis, E., Bollen, M.H. and Gu, I.Y. (2002) Expert System for Classification and Analysis of Power System Events. IEEE Transactions on Power Delivery, 17, 423-428. https://doi.org/10.1109/61.997911

[111] Macias, J.R. and Exposito, A.G. (2006) Self-Tuning of Kalman Filters for Harmonic Computation. IEEE Transactions on Power Delivery, 21, 501-503. https://doi.org/10.1109/TPWRD.2005.860411

[112] Perez, E. and Barros, J. (2008) An Extended Kalman Filtering Approach for Detection and Analysis of Voltage Dips in Power Systems. Electric Power Systems Research, 78, 618-625. https://doi.org/10.1016/j.epsr.2007.05.006

[113] Masoum, M.A.S., Jamali, S. and Ghaffarzadeh, N. (2010) Detection and Classification of Power Quality Disturbances Using Discrete Wavelet Transform and Wavelet Networks. IET Science, Measurement \& Technology, 4, 193-205. https://doi.org/10.1049/iet-smt.2009.0006

[114] Manimala, K., Selvi, K. and Ahila, R. (2011) Hybrid Soft Computing Techniques for Feature Selection and Parameter Optimization in Power Quality Data Mining. Applied Soft Computing, 11, 5485-5497. https://doi.org/10.1016/j.asoc.2011.05.010

[115] De la Rosa, J.J.G., Agüera-Pérez, A., Palomares-Salas, J.C., Sierra-Fernández, J.M. and Moreno-Muñoz, A. (2012) A Novel Virtual Instrument for Power Quality Surveillance Based on Higher-Order Statistics and Case-Based Reasoning. Measurement, 45, 1824-1835. https://doi.org/10.1016/j.measurement.2012.03.036

[116] Balouji, E. and Salor, O. (2017) Classification of Power Quality Events Using Deep Learning on Event Images. 2017 3rd International Conference on Pattern Recognition and Image Analysis, Shahrekord, 19-20 April 2017, 216-221. 
https://doi.org/10.1109/PRIA.2017.7983049

[117] Ma, J., Zhang, J., Xiao, L., Chen, K. and Wu, J. (2017) Classification of Power Quality Disturbances via Deep Learning. IETE Technical Review, 34, 408-415. https://doi.org/10.1080/02564602.2016.1196620

[118] Ferreira, D.D., de Seixas, J.M. and Cerqueira, A.S. (2015) A Method Based on Independent Component Analysis for Single and Multiple Power Quality Disturbance Classifications. Electric Power Systems Research, 119, 425-431. https://doi.org/10.1016/j.epsr.2014.10.028

[119] Zyabkina, O., Domagk, M., Meyer, J. and Schegner, P. (2016) Classification and Identification of Anomalies in Time Series of Power Quality Measurements. 2016 IEEE PES Innovative Smart Grid Technologies Conference Europe, Ljubljana, 9-12 October 2016, 1-6. https://doi.org/10.1109/ISGTEurope.2016.7856290

[120] Saputra, I.D., Smith, J.S., Jiang, L. and Wu, Q.H. (2016) Detection and Classification of Power Disturbances Using Half Multi-Resolution Morphology Gradient. 2016 IEEE PES Innovative Smart Grid Technologies Conference Europe, Ljubljana, 9-12 October 2016, 1-5. https://doi.org/10.1109/ISGTEurope.2016.7856263

[121] Gharavi, H. and Hu, B. (2017) Space-Time Approach for Disturbance Detection and Classification. IEEE Transactions on Smart Grid, PP, 1.

[122] Ahsan, M.K., Pan, T.H. and Li, Z.M. (2018) Intelligent Control System to Detect, Classify and Reserve Power Quality in Micro Grid through Multi-Agent System. American Journal of Engineering, Technology and Society, 5, 30-52.

[123] Ibrahim, W.A. and Morcos, M.M. (2002) Artificial Intelligence and Advanced Mathematical Tools for Power Quality Applications: A Survey. IEEE Transactions on Power Delivery, 17, 668-673. https://doi.org/10.1109/61.997958

[124] Saini, M.K. and Kapoor, R. (2012) Classification of Power Quality Events-A Review. International Journal of Electrical Power \& Energy Systems, 43, 11-19. https://doi.org/10.1016/j.ijepes.2012.04.045

[125] Ghosh, A.K. and Lubkeman, D.L. (1994) The Classification of Power System Disturbance Waveforms Using a Neural Network Approach. IEEE Transactions on Power Delivery, 10, 109-115. https://doi.org/10.1109/61.368408

[126] Dilokratanatrakool, C., Ayudhya, P.N., Chayavanich, T. and Prapanavarat, C. (2003) Automatic Detection-Localization of Fault Point on Waveform and Classification of Power Quality Disturbance Waveshape Fault Using Wavelet and Neural Network. Proceedings of the IEEE International Conference on Robotics, Intelligent Systems and Signal Processing, 1, 142-147.

[127] Srinivasan, D., Ng, W.S. and Liew, A.C. (2006) Neural-Network-Based Signature Recognition for Harmonic Source Identification. IEEE Transactions on Power Delivery, 21, 398-405. https://doi.org/10.1109/TPWRD.2005.852370

[128] Silva, K.M., Souza, B.A. and Brito, N.S. (2006) Fault Detection and Classification in Transmission Lines Based on Wavelet Transform and ANN. IEEE Transactions on Power Delivery, 21, 2058-2063. https://doi.org/10.1109/TPWRD.2006.876659

[129] Cesar, D.G., Valdomiro, V.G. and Gabriel, O.P. (2006) Automatic Power Quality Disturbances Detection and Classification Based on Discrete Wavelet Transform and artificial Intelligence. 2006 IEEE/ PES Transmission \& Distribution Conference and Exposition: Latin America, Caracas, 15-18 August 2006, 1-6.

https://doi.org/10.1109/TDCLA.2006.311515

[130] Chandel, A.K., Guleria, G. and Chandel, R. (2008) Classification of Power Quality Problems Using Wavelet-Based Artificial Neural Network. 2008 IEEE/PES Transmission and Distribution Conference and Exposition, Chicago, IL, 21-24 April 
2008, 1-5. https://doi.org/10.1109/TDC.2008.4517083

[131] Talaat, N. and Ilic, M. (2008) ANNs Based on Subtractive Cluster Feature for Classifying Power Quality. 200840 th North American Power Symposium, Calgary, AB, 28-30 September 2008, 1-7.

[132] Huang, N., Xu, D., Liu, X. and Lin, L. (2012) Power Quality Disturbances Classification Based on S-Transform and Probabilistic Neural Network. Neurocomputing, 98, 12-23. https://doi.org/10.1016/j.neucom.2011.06.041

[133] Biswal, B., Biswal, M., Mishra, S. and Jalaja, R. (2014) Automatic Classification of Power Quality Events Using Balanced Neural Tree. IEEE Transactions on Industrial Electronics, 61, 521-530. https://doi.org/10.1109/TIE.2013.2248335

[134] Valtierra-Rodriguez, M., de Jesus Romero-Troncoso, R., Osornio-Rios, R.A. and Garcia-Perez, A. (2014) Detection and Classification of Single and Combined Power Quality Disturbances Using Neural Networks. IEEE Transactions on Industrial Electronics, 61, 2473-2482. https://doi.org/10.1109/TIE.2013.2272276

[135] Liao, C.C. (2010) Enhanced RBF Network for Recognizing Noise-Riding Power Quality Events. IEEE Transactions on Instrumentation and Measurement, 59, 1550-1561. https://doi.org/10.1109/TIM.2009.2027769

[136] Mahela, O.P., Shaik, A.G. and Gupta, N. (2015) A Critical Review of Detection and Classification of Power Quality Events. Renewable and Sustainable Energy Reviews, 41, 495-505. https://doi.org/10.1016/j.rser.2014.08.070

[137] Jayasree, T., Devaraj, D. and Sukanesh, R. (2009) Power Quality Disturbance Classification Using S-Transform and Radial Basis Network. Applied Artificial Intelligence, 23, 680-693. https://doi.org/10.1080/08839510903205563

[138] Tan, R.H.G. and Ramachandramurthy, V.K. (2010) Numerical Model Framework of Power Quality Disturbances. European Journal of Scientific Research, 43, 30-47.

[139] Mohod, S.B. and Ghate, V.N. (2015) MLP-Neural Network-Based Detection and Classification of Power Quality Disturbances. 2015 International Conference on Energy Systems and Applications, Pune, 30 October-1 November 2015, 124-129. https://doi.org/10.1109/ICESA.2015.7503325

[140] Chen, Z.M., Li, M.S., Ji, T.Y. and Wu, Q.H. (2016) Detection and Classification of Power Quality Disturbances in Time Domain Using Probabilistic Neural Network. 2016 International Joint Conference on Neural Networks (IJCNN), Vancouver, BC, 24-29 July 2016, 1277-1282. https://doi.org/10.1109/IJCNN.2016.7727344

[141] Alshahrani, S., Abbod, M. and Taylort, G. (2016) Detection and Classification of Power Quality Disturbances Based on Hilbert-Huang Transform and Feed forward Neural Networks. 201651 st International Universities Power Engineering Conference, 6-9 September 2016, Coimbra, 1-6. https://doi.org/10.1109/UPEC.2016.8114075

[142] Khadse, C.B., Chaudhari, M.A. and Borghate, V.B. (2016) Conjugate Gradient Back-Propagation Based Artificial Neural Network for Real-Time Power Quality Assessment. International Journal of Electrical Power \& Energy Systems, 82, 197-206. https://doi.org/10.1016/j.ijepes.2016.03.020

[143] Martinez-Figueroa, G.D.J., Morinigo-Sotelo, D., Zorita-Lamadrid, A.L., Morales-Velazquez, L. and Romero-Troncoso, R.D.J. (2017) FPGA-Based Smart Sensor for Detection and Classification of Power Quality Disturbances Using Higher Order Statistics. IEEE Access, 5, 14259-14274. https://doi.org/10.1109/ACCESS.2017.2732726

[144] Ajil, K.S., Thapliyal, P.K., Shukla, M.V., Pal, P.K., Joshi, P.C. and Navalgund, R.R. (2010) A New Technique for Temperature and Humidity Profile Retrieval from 
Infrared-Sounder Observations Using the Adaptive Neuro-Fuzzy Inference System. IEEE Transactions on Geoscience and Remote Sensing, 48, 1650-1659. https://doi.org/10.1109/TGRS.2009.2037314

[145] Mizutani, E. and Nishio, K. (2002) Multi-Illuminant Color Reproduction for Electronic Cameras via CANFIS Neuro-Fuzzy Modular Network Device Characterization. IEEE Transactions on Neural Networks, 13, 1009-1022. https://doi.org/10.1109/TNN.2002.1021900

[146] Chang, J., Han, G., Valverde, J.M., Griswold, N.C., Duque-Carrillo, J.F. and Sanchez-Sinencio, E. (1997) Cork Quality Classification System Using a Unified Image Processing and Fuzzy-Neural Network Methodology. IEEE Transactions on Neural Networks, 8, 964-974. https://doi.org/10.1109/72.595897

[147] Pires, V.F., Amaral, T.G. and Martins, J.F. (2011) Power Quality Disturbances Classification Using the 3-D Space Representation and PCA Based Neuro-Fuzzy Approach. Expert Systems with Applications, 38, 11911-11917.

https://doi.org/10.1016/j.eswa.2011.03.083

[148] Reddy, M.J. and Mohanta, D.K. (2008) Adaptive-Neuro-Fuzzy Inference System Approach for Transmission Line Fault Classification and Location Incorporating Effects of Power Swings. IET Generation, Transmission \& Distribution, 2, 235-244. https://doi.org/10.1049/iet-gtd:20070079

[149] Reddy, M.J.B. and Mohanta, D.K. (2008) Performance Evaluation of an Adaptive-Network-Based Fuzzy Inference System Approach for Location of Faults on Transmission Lines Using Monte Carlo Simulation. IEEE Transactions on Fuzzy Systems, 16, 909-919. https://doi.org/10.1109/TFUZZ.2008.924210

[150] Kumar, G.S., Kumar, B.K. and Mishra, M.K. (2011) Mitigation of Voltage Sags with Phase Jumps by UPQC with PSO-Based ANFIS. IEEE Transactions on Power Delivery, 26, 2761-2773. https://doi.org/10.1109/TPWRD.2011.2165301

[151] Dash, P., Chakravorti, T. and Patnaik, R. (2017) Advanced Signal Processing Techniques for Multiclass Disturbance Detection and Classification in Microgrids. IET Science, Measurement \& Technology, 11, 504-515. https://doi.org/10.1049/iet-smt.2016.0432

[152] Dhimish, M., Holmes, V., Mehrdadi, B., Dales, M. and Mather, P. (2017) Photovoltaic Fault Detection Algorithm Based on Theoretical Curves Modeling and Fuzzy Classification System. Energy, 140, 276-290. https://doi.org/10.1016/j.energy.2017.08.102

[153] Chakraborty, S., Chatterjee, A. and Goswami, S.K. (2017) DTCWT Based Approach for Power Quality Disturbance Recognition. In: Computer, Communication and Electrical Technology: Proceedings of the International Conference on Advancement of Computer Communication and Electrical Technology (ACCET 2016), CRC Press, London, 209. https://doi.org/10.1201/9781315400624-42

[154] Vapnik, V. (2013) The Nature of Statistical Learning Theory. Springer Science \& Business Media, Berlin, Heidelberg, Germany.

[155] Khasnobish, A., Bhattacharyya, S., Konar, A., Tibarewala, D.N. and Nagar, A.K. (2011) A Two-Fold Classification for a Composite Decision about Localized Arm Movement from EEG by SVM and QDA Techniques. The 2011 International Joint Conference on Neural Networks, San Jose, CA, 31 July-5 August 2011, 1344-1351. https://doi.org/10.1109/IJCNN.2011.6033380

[156] Lv, G., Wang, X., Zhang, H. and Zhang, C. (2005) PQ Disturbances Identification Based on SVMs Classifier. 2005 International Conference on Neural Networks and Brain, Beijing, 13-15 October 2011, 222-226. 
https://doi.org/10.1109/ICNNB.2005.1614602

[157] Janik, P. and Lobos, T. (2006) Automated Classification of Power-Quality Disturbances Using SVM and RBF Networks. IEEE Transactions on Power Delivery, 21, 1663-1669. https://doi.org/10.1109/TPWRD.2006.874114

[158] Lin, W.M., Wu, C.H., Lin, C.H. and Cheng, F.S. (2006) Classification of Multiple Power Quality Disturbances Using Support Vector Machine and One-versus-One Approach. 2006 International Conference on Power System Technology, Chongqing, 22-26 October 2006, 1-8. https://doi.org/10.1109/ICPST.2006.321956

[159] Cerqueira, A.S., Ferreira, D.D., Ribeiro, M.V. and Duque, C.A. (2008) Power Quality Events Recognition Using a SVM-Based Method. Electric Power Systems Research, 78, 1546-1552. https://doi.org/10.1016/j.epsr.2008.01.016

[160] Janik, P. and Lobos, T. (2006) Automated Classification of Power Quality Disturbances Using SVM and RBF Networks. IEEE Transactions on Power Delivery, 21, 1663-1669. https://doi.org/10.1109/TPWRD.2006.874114

[161] Ekici, S. (2009) Classification of Power System Disturbances Using Support Vector Machines. Expert Systems with Applications, 36, 9859-9868. https://doi.org/10.1016/j.eswa.2009.02.002

[162] Panigrahi, B.K., Dash, P.K. and Reddy, J.B.V. (2009) Hybrid Signal Processing and Machine Intelligence Techniques for Detection, Quantification, and Classification of Power Quality Disturbances. Engineering Applications of Artificial Intelligence, 22, 442-454. https://doi.org/10.1016/j.engappai.2008.10.003

[163] Erişti, H. and Demir, Y. (2010) A New Algorithm for Automatic Classification of Power Quality Events Based on Wavelet Transform and SVM. Expert Systems with Applications, 37, 4094-4102. https://doi.org/10.1016/j.eswa.2009.11.015

[164] Erişti, H., Uçar, A. and Demir, Y. (2010) Wavelet-Based Feature Extraction and Selection for Classification of Power System Disturbances Using Support Vector Machines. Electric Power Systems Research, 80, 743-752. https://doi.org/10.1016/j.epsr.2009.09.021

[165] Moravej, Z., Abdoos, A.A. and Pazoki, M. (2009) Detection and Classification of Power Quality Disturbances Using Wavelet Transform and Support Vector Machines. Electric Power Components and Systems, 38, 182-196. https://doi.org/10.1080/15325000903273387

[166] Biswal, B., Biswal, M.K., Dash, P.K. and Mishra, S. (2013) Power Quality Event Characterization Using Support Vector Machine and Optimization Using Advanced Immune Algorithm. Neurocomputing, 103, 75-86.

https://doi.org/10.1016/j.neucom.2012.08.031

[167] Palomares-Salas, J.C., Agüera-Pérez, A. and de la Rosa, J.J.G. (2011) Support Vector Machine for Power Quality Disturbances Classification Using Higher-Order Statistical Features. 20117 th International Conference-Workshop Compatibility and Power Electronics, Tallinn, 1-3 June 2011, 6-10. https://doi.org/10.1109/CPE.2011.5942198

[168] Thirumala, K., Umarikar, A.C. and Jain, T. (2016) A New Classification Model Based on SVM for Single and Combined Power Quality Disturbances. 2016 National Power Systems Conference (NPSC), Bhubaneswar, 19-21 December 2016, 1-6. https://doi.org/10.1109/NPSC.2016.7858889

[169] Abdoos, A.A., Mianaei, P.K. and Ghadikolaei, M.R. (2016) Combined VMD-SVM Based Feature Selection Method for Classification of Power Quality Events. Applied Soft Computing, 38, 637-646. https://doi.org/10.1016/j.asoc.2015.10.038

[170] Cho, M.Y. and Hoang, T.T. (2017) Feature Selection and Parameters Optimization 
of SVM Using Particle Swarm Optimization for Fault Classification in Power Distribution Systems. Computational Intelligence and Neuroscience, 2017, Article ID: 4135465. https://doi.org/10.1155/2017/4135465

[171] Naderian, S. and Salemnia, A. (2017) An Implementation of Type-2 Fuzzy Kernel-Based Support Vector Machine Algorithm for Power Quality Events Classification. International Transactions on Electrical Energy Systems, 27, e2303. https://doi.org/10.1002/etep.2303

[172] Holland, J.H. and Goldberg, D. (1989) Genetic Algorithms in Search, Optimization and Machine Learning. Addison-Wesley, Reading, MA.

[173] Levitin, G., Kalyuzhny, A., Shenkman, A. and Chertkov, M. (2000) Optimal Capacitor Allocation in Distribution Systems Using a Genetic Algorithm and a Fast Energy Loss Computation Technique. IEEE Transactions on Power Delivery, 15, 623-628. https://doi.org/10.1109/61.852995

[174] Kung, C.H., Devaney, M.J., Huang, C.M. and Kung, C.M. (1998) Fuzzy-Based Adaptive Digital Power Metering Using a Genetic Algorithm. IEEE Transactions on Instrumentation and Measurement, 47, 183-188. https://doi.org/10.1109/19.728815

[175] El-Zonkoly, A.M. (2005) Power System Model Validation for Power Quality Assessment Applications Using Genetic Algorithm. Expert Systems with Applications, 29, 941-944. https://doi.org/10.1016/j.eswa.2005.06.013

[176] El-Naggar, K.M. and Al-Hasawi, W.M. (2006) A Genetic-Based Algorithm for Measurement of Power System Disturbances. Electric Power Systems Research, 76, 808-814. https://doi.org/10.1016/j.epsr.2005.06.012

[177] Ma, H.M., Ng, K.T. and Man, K.F. (2008) Multiobjective Coordinated Power Voltage Control Using Jumping Genes Paradigm. IEEE Transactions on Industrial Electronics, 55, 4075-4084. https://doi.org/10.1109/TIE.2008.928107

[178] Hong, Y.Y. and Chen, Y.Y. (2011) Placement of Power Quality Monitors Using Enhanced Genetic Algorithm and Wavelet Transform. IET Generation, Transmission \& Distribution, 5, 461-466. https://doi.org/10.1049/iet-gtd.2010.0397

[179] Wang, M.H. and Tseng, Y.F. (2011) A Novel Analytic Method of Power Quality Using Extension Genetic Algorithm and Wavelet Transform. Expert Systems with Applications, 38, 12491-12496. https://doi.org/10.1016/j.eswa.2011.04.032

[180] Sánchez, P., Montoya, F.G., Manzano-Agugliaro, F. and Gil, C. (2013) A Genetic Algorithm for S-Transform Optimisation in the Analysis and Classification of Electrical Signal Perturbations. Expert Systems with Applications, 40, 6766-6777. https://doi.org/10.1016/j.eswa.2013.06.055

[181] Jaen-Cuellar, A.Y., Morales-Velazquez, L., de Jesus Romero-Troncoso, R., Moriñigo-Sotelo, D. and Osornio-Rios, R.A. (2016) Micro-Genetic Algorithms for Detecting and Classifying Electric Power Disturbances. Neural Computing and Applications, 28, 379-392. https://doi.org/10.1007/s00521-016-2355-Z

[182] Phan, A.V., Le Nguyen, M. and Bui, L.T. (2017) Feature Weighting and SVM Parameters Optimization Based on Genetic Algorithms for Classification Problems. Applied Intelligence, 46, 455-469. https://doi.org/10.1007/s10489-016-0843-6

[183] John, Y. and Langari, R. (1999) Fuzzy Logic: Intelligence, Control, and Information. Dorling Kindersley, India, 379-383.

[184] Chacon, M.I., Duran, J.L. and Santiesteban, L.A. (2007) A Wavelet-Fuzzy logic Based System to Detect and Identify Electric Power Disturbances. 2007 IEEE Symposium on Computational Intelligence in Image and Signal Processing, Honolulu, HI, 1-5 April 2007, 52-57. https://doi.org/10.1109/CIISP.2007.369293 
[185] Bizjak, B. and Planinsic, P. (2006) Classification of Power Disturbances Using Fuzzy Logic. 2006 12 th International Power Electronics and Motion Control Conference, Portoroz, 30 August-1 September 2006, 1356-1360.

[186] Liao, Y. and Lee, J.B. (2004) A Fuzzy-Expert System for Classifying Power Quality Disturbances. International Journal of Electrical Power \& Energy Systems, 26, 199-205. https://doi.org/10.1016/j.ijepes.2003.10.012

[187] Meher, S.K. and Pradhan, A.K. (2010) Fuzzy Classifiers for Power Quality Events Analysis. Electric Power Systems Research, 80, 71-76. https://doi.org/10.1016/j.epsr.2009.08.014

[188] Abdelsalam, A.A., Eldesouky, A.A. and Sallam, A.A. (2012) Characterization of Power Quality Disturbances Using Hybrid Technique of Linear Kalman Filter and Fuzzy-Expert System. Electric Power Systems Research, 83, 41-50.

https://doi.org/10.1016/j.epsr.2011.09.018

[189] Hooshmand, R. and Enshaee, A. (2010) Detection and Classification of Single and Combined Power Quality Disturbances Using Fuzzy Systems Oriented by Particle Swarm Optimization Algorithm. Electric Power Systems Research, 80, 1552-1561. https://doi.org/10.1016/j.epsr.2010.07.001

[190] Biswal, B., Behera, H.S., Bisoi, R. and Dash, P.K. (2012) Classification of Power Quality Data Using Decision Tree and Chemotactic Differential Evolution Based Fuzzy Clustering. Swarm and Evolutionary Computation, 4, 12-24. https://doi.org/10.1016/j.swevo.2011.12.003

[191] Behera, H.S., Dash, P.K. and Biswal, B. (2010) Power Quality Time Series Data Mining Using S-Transform and Fuzzy Expert System. Applied Soft Computing, 10, 945-955. https://doi.org/10.1016/j.asoc.2009.10.013

[192] Biswal, B., Dash, P.K. and Panigrahi, B.K. (2009) Power Quality Disturbance Classification Using Fuzzy C-Means Algorithm and Adaptive Particle Swarm Optimization. IEEE Transactions on Industrial Electronics, 56, 212-220. https://doi.org/10.1109/TIE.2008.928111

[193] Dash, P.K., Mishra, S., Salama, M.A. and Liew, A.C. (2000) Classification of Power System Disturbances Using a Fuzzy Expert System and a Fourier Linear Combiner. IEEE Transactions on Power Delivery, 15, 472-477. https://doi.org/10.1109/61.852971

[194] Zhu, T.X., Tso, S.K. and Lo, K.L. (2004) Wavelet-Based Fuzzy Reasoning Approach to Power-Quality Disturbance Recognition. IEEE Transactions on Power Delivery, 19, 1928-1935. https://doi.org/10.1109/TPWRD.2004.832382

[195] Ibrahim, W.R.A. and Morcos, M.M. (2006) An Adaptive Fuzzy Self-Learning Technique for Prediction of Abnormal Operation of Electrical Systems. IEEE Transactions on Power Delivery, 21, 1770-1777. https://doi.org/10.1109/TPWRD.2006.881795

[196] Ibrahim, W.R.A. and Morcos, M.M. (2005) Novel Data Compression Technique for Power Waveforms Using Adaptive Fuzzy Logic. IEEE Transactions on Power Delivery, 20, 2136-2143. https://doi.org/10.1109/TPWRD.2005.848458

[197] Chakravorti, T. and Dash, P.K. (2016, December) Morphology-Based Fuzzy Approach for Detection \& Classification of Simultaneous Power Quality Disturbances. 2016 IEEE Annual India Conference (INDICON), Bangalore, 16-18 December 2016, 1-6. https://doi.org/10.1109/INDICON.2016.7838926

[198] Sundaram, P.K. and Neela, R. (2016) Electric Power Quality Events Classification Using Kalman Filter and Fuzzy Expert System. International Journal of Applied Engineering Research, 11, 5956-5962. 
[199] Sundaram, P.K. and Neela, R. (2016) Automatic Recognition of Power Quality Disturbances Using Kalman Filter and Fuzzy Expert System. International Journal of Computer Applications, 149, 16-23. https://doi.org/10.5120/ijca2016911353

[200] Sundaram, P.K. and Neela, R. (2016) Hilbert Transform Based Fuzzy Expert System for Diagnosing and Classifying Power Quality Disturbances. International Journal of Computer Applications, 142, 48-55. https://doi.org/10.5120/ijca2016909729

[201] Sahu, G., Biswal, B. and Choubey, A. (2017) Non-Stationary Signal Classification via Modified Fuzzy C-Means Algorithm and Improved Bacterial Foraging Algorithm. International Journal of Numerical Modelling. Electronic Networks, Devices, and Fields, 30, e2181. https://doi.org/10.1002/jnm.2181

[202] Rodríguez, A., Aguado, J.A., Martín, F., López, J.J., Muñoz, F. and Ruiz, J.E. (2012) Rule-Based Classification of Power Quality Disturbances Using S-Transform. Electric Power Systems Research, 86, 113-121. https://doi.org/10.1016/j.epsr.2011.12.009

[203] Salem, M.E., Mohamed, A. and Samad, S.A. (2010) A Rule-Based System for Power Quality Disturbance Classification Incorporating S-Transform Features. Expert Systems with Applications, 37, 3229-3235. https://doi.org/10.1016/j.eswa.2009.09.057

[204] Zheng, G., Shi, M.X., Liu, D., Yao, J. and Miao, Z.M. (2002) Power Quality Disturbance Classification Based on Rule-Based and Wavelet-Multi-Resolution Decomposition. Proceedings of the International Conference on Machine Learning and Cybernetics, 4, 2137-2141. https://doi.org/10.1109/ICMLC.2002.1175416

[205] Reddy, M.V. and Sodhi, R. (2016) A Rule-Based S-Transform and AdaBoost Based Approach for Power Quality Assessment. Electric Power Systems Research, 134, 66-79. https://doi.org/10.1016/j.epsr.2016.01.003

[206] Liu, H., Hussain, F. and Shen, Y. (2017) Power Quality Disturbances Classification Using Compressive Sensing and Maximum Likelihood. IETE Technical Review, 1-10. https://doi.org/10.1080/02564602.2017.1304290

[207] Reaz, M.B.I., Choong, F., Sulaiman, M.S., Mohd-Yasin, F. and Kamada, M. (2007) Expert System for Power Quality Disturbance Classifier. IEEE Transactions on Power Delivery, 22, 1979-1988. https://doi.org/10.1109/TPWRD.2007.899774

[208] Yu, J., Wang, L., Zhou, B. and Tian, W. (2011, August) An Expert System Based on s-Transform for Classification of Voltage Dips. 2011 2nd International Conference on Artificial Intelligence, Management Science and Electronic Commerce (AIMSEC), Deng Leng, 8-10 August 2011, 3732-3735.

[209] Ferrero, A. and Salicone, S. (2005) An Easy VI Program to Detect Transient Disturbances in the Supply Voltage. IEEE Transactions on Instrumentation and Measurement, 54, 1471-1474. https://doi.org/10.1109/TIM.2005.851078

[210] Ramos, P.M., Janeiro, F.M. and Serra, A.C. (2008) PQ Monitoring System for Real-Time Detection and Classification of Disturbances in a Single-Phase Power System. IEEE Transactions on Instrumentation and Measurement, 57, 1725-1733. https://doi.org/10.1109/TIM.2008.925345

[211] Youssef, A.M., Abdel-Galil, T.K., El-Saadany, E.F. and Salama, M.M.A. (2004) Disturbance Classification is Utilizing Dynamic Time Warping Classifier. IEEE Transactions on Power Delivery, 19, 272-278. https://doi.org/10.1109/TPWRD.2003.820178

[212] Khosravi, A., Meléndez, J. and Colomer, J. (2009) Classification of Sags Gathered in Distribution Substations Based on Multiway Principal Component Analysis. Electric Power Systems Research, 79, 144-151.

https://doi.org/10.1016/j.epsr.2008.05.014 
[213] Moreto, M. and Rolim, J.G. (2011) Using Phasor Data Records and Sequence of Events to Automate the Classification of Disturbances of Power Generating Units. Electric Power Systems Research, 81, 1266-1273. https://doi.org/10.1016/j.epsr.2011.01.008

[214] Abdel-Galil, T.K., Kamel, M., Youssef, A.M., El-Saadany, E.F. and Salama, M.M.A. (2004) Power Quality Disturbance Classification Using the Inductive Inference Approach. IEEE Transactions on Power Delivery, 19, 1812-1818. https://doi.org/10.1109/TPWRD.2003.822533

[215] De Yong, D., Reineri, C. and Magnago, F. (2013) Educational Software for Power Quality Analysis. IEEE Latin America Transactions, 11, 479-485. https://doi.org/10.1109/TLA.2013.6502849

[216] Lima, R., Quiroga, D., Reineri, C. and Magnago, F. (2008) Hardware and Software Architecture for Power Quality Analysis. Computers \& Electrical Engineering, 34, 520-530. https://doi.org/10.1016/j.compeleceng.2007.12.003

[217] Salem, M.E., Mohamed, A., Samad, S.A. and Yahya, I. (2007) Software Tool for Real-Time Power Quality Disturbance Analysis and Classification. 2007 5th Student Conference on Research and Development, Selangor, Malaysia, 12-11 December 2007, 1-5. https://doi.org/10.1109/SCORED.2007.4451390

[218] Abdel-Galil, T.K., El-Saadany, E.F., Youssef, A.M. and Salama, M.M.A. (2005) Disturbance Classification Using Hidden Markov Models and Vector Quantization. IEEE Transactions on Power Delivery, 20, 2129-2135. https://doi.org/10.1109/TPWRD.2004.843399

[219] Gaouda, A.M., Kanoun, S.H. and Salama, M.M.A. (2001) On-Line Disturbance Classification Using Nearest Neighbor Rule. Electric Power Systems Research, 57, 1-8. https://doi.org/10.1016/S0378-7796(00)00120-6

[220] Daponte, P., Di Penta, M. and Mercurio, G. (2004) TransientMeter: A Distributed Measurement System for Power Quality Monitoring. IEEE Transactions on Power Delivery, 19, 456-463. https://doi.org/10.1109/TPWRD.2004.825200

[221] Wang, X., Bi, G.H., Chen, S.L. and Zu, Z. (2011) A Method to Analyze Power System Quality Disturbing Signal Based on Recurrence Quantification Analysis. Procedia Engineering, 15, 4115-4121. https://doi.org/10.1016/j.proeng.2011.08.772

[222] Kim, H.J., Shim, J.W., Sim, K. and Hur, K. (2013) Assessment of Improved Power Quality Due to Fault Current Limiting HTS Cable. IEEE Transactions on Applied Superconductivity, 23, 5602104-5602104. https://doi.org/10.1109/TASC.2012.2235500

[223] Dugan, R.C., McGranaghan, M.F., et al. (2012) Electrical Power Systems Quality. McGraw-Hill Education, New York, USA.

[224] Rodriguez-Guerrero, M.A., Carranza-Lopez-Padilla, R., Osornio-Rios, R.A. and Romero-Troncoso, R.D.J. (2017) A Novel Methodology for Modeling Waveforms for Power Quality Disturbance Analysis. Electric Power Systems Research, 143, 14-24. https://doi.org/10.1016/j.epsr.2016.09.003

[225] Hua, L., Baoqun, Z. and Guangjian, W. (2007) Application of Wavelet Network for Automatic Power Quality Disturbances Recognition in Distribution Power System. 2007 Chinese Control Conference, Hunan, 26-31 July 2007, 254-258.

[226] Panigrahi, B.K. and Sinha, S.K. (2006) Detection and Classification of Non-Stationary Power Disturbances in Noisy Conditions. 2006 International Conference on Power Electronic, Drives and Energy Systems, New Delhi, 12-15 December 2006, 1-5. https://doi.org/10.1109/PEDES.2006.344258

[227] Ozgonenel, O., Yalcin, T., Guney, I. and Kurt, U. (2013) A New Classification for 
Power Quality Events in Distribution System. Electric Power Systems Research, 95, 192-199. https://doi.org/10.1016/j.epsr.2012.09.007

[228] Hu, W.B., Li, K.C., Zhao, D.J. and Xie, B.R. (2007) Performance Improvement of Power Quality Disturbance Classification Based on a New De-Noising Technique. 2007 International Conference on Electrical Machines and Systems (ICEMS), Seoul, 8-11 October 2007, 1806-1810.

[229] Liao, CC. and Yang, H.T. (2009) Recognizing Noise-Influenced Power Quality Events with Integrated Feature Extraction and Neuro-Fuzzy Network. IEEE Transactions on Power Delivery, 24, 2132-2141. https://doi.org/10.1109/TPWRD.2009.2016789

[230] Dwivedi, U.D. and Singh, S.N. (2010) Enhanced Detection of Power-Quality Events Using Intro and Interscale Dependencies of Wavelet Coefficients. IEEE Transactions on Power Delivery, 25, 358-366.

https://doi.org/10.1109/TPWRD.2009.2027482

[231] Liao, C.C., Yang, H.T. and Chang, H.H. (2011) Denoising Techniques with a Spatial Noise-Suppression Method for Wavelet-Based Power Quality Monitoring. IEEE Transactions on Instrumentation and Measurement, 60, 1986-1996. https://doi.org/10.1109/TIM.2011.2115610

[232] Park, M., Kim, D. and Oh, H.S. (2015) Quantile-Based Empirical Mode Decomposition: An Efficient Way to Decompose Noisy Signals. IEEE Transactions on Instrumentation and Measurement, 64, 1802-1813. https://doi.org/10.1109/TIM.2014.2381355

[233] Hao, H., Wang, H.L. and Rehman, N.U. (2017) A Joint Framework for Multivariate Signal Denoising Using Multivariate Empirical Mode Decomposition. Signal Processing, 135, 263-273. https://doi.org/10.1016/j.sigpro.2017.01.022

[234] Guo, B., Peng, S., Hu, X. and Xu, P. (2017) Complex-Valued Differential Operator-Based Method for Multi-Component Signal Separation. Signal Processing, 132, 66-76. https://doi.org/10.1016/j.sigpro.2016.09.015 